\title{
Regional Industrial Structure and Agglomeration Economies: An Analysis of Productivity in Three Manufacturing Industries
}

\begin{abstract}
We investigate whether a more concentrated regional industrial structure - the dominance of a few large firms in a given industry in a region - limits agglomeration economies and ultimately diminishes the economic performance of firms in that industry, especially small ones. In an application to three industries using establishment-level production functions and a combination of confidential and publicly available data sources, we find a consistently negative and substantial direct productivity effect associated with regional industrial structure concentration and only mixed and relatively weak evidence that agglomeration economies are a mediating factor in that effect.
\end{abstract}

Keywords: industrial structure; agglomeration economies; manufacturing; productivity; small firms

JEL codes: L11 (size distribution of firms); O10 (economic development); R30 (production analysis and firm location) 


\section{Regional Industrial Structure and Agglomeration Economies:}

\section{An Analysis of Productivity in Three Manufacturing Industries}

\section{INTRODUCTION}

Small manufacturing plants located in regions where their own industry is dominated by a few large firms may be less able to capture the benefits of agglomeration economies than plants in regions with a less concentrated industrial structure. ${ }^{1}$ The reasons are several. First, a highly concentrated industrial structure implies a narrower range of local specialized producer inputs and services. Large firms are more likely to source inputs from nonlocal suppliers, either via internal supply (vertical integration) or national contracts, thus reducing the size of the local market for independent specialized suppliers (Enright 1995; Porter 1998; Henderson et al. 2001). When local suppliers are present, they may be functionally and strategically linked to a large local manufacturer; they may favor the stability of large volume contracts and therefore be less inclined to work with smaller producers; or they may generally be more responsive to the needs of producers with the most buying power (Nelson and Winter 1982; Booth 1986). Second, the most productive workers, particularly those with specialized skill sets and experience, may gravitate toward the largest and most stable employers, reducing labor pooling economies for the full range of producers in a region (Audretsch 2001). Third, networking among firms may be lower where an industry's structure is highly concentrated, decreasing knowledge spillovers among firms in that local industry (Chinitz 1961; Saxenian 1994; Carree and Thurik 1999; Scherer 1980; Glaeser et al. 1992; Malmberg and Maskell 2002).

\footnotetext{
1 This material is based upon work supported by awards from the National Science Foundation (Grant BCS0423900), the Ewing Marion Kauffman Foundation, and the North American Regional Science Council. Any opinions and conclusions expressed herein are those of the authors and do not necessarily represent the views of the United States Census Bureau or any of the supporting organizations. All results have been reviewed to ensure that no confidential information is disclosed. Support for this research at the Triangle Census Research Data Center from the National Science Foundation (ITR-0427889) is also gratefully acknowledged.
} 
Although empirical evidence of a link between local industrial structure and agglomeration economies does exist, most of it is indirect. There are a growing number of studies of the influence of industrial diversity and average establishment size on productivity, employment growth, innovation, and business start-ups (e.g., Quigley 1998; Hanson 2001; Dissart 2003; Henderson 2003; Glaeser and Kerr 2008; Glaeser et al. 2009). However, crossindustry diversity is a different concept than own-industry structure and, since multiestablishment firms are common in any given location, average establishment size is only a rough indicator of industrial structure (Evans 1986). Measuring regional industrial structure concentration is difficult because micro-level data are necessary to construct an appropriate firmbased indicator. Case studies of industrial structure in particular regions are suggestive but have limited generalizability (some examples are Scott 1988; Saxenian 1994; Enright 1995; Rantisi 2002; Watts et al. 2003). At the national rather than regional scale, empirical findings suggest that a concentrated industrial structure can affect firms' performance either negatively or positively, depending on the level of concentration (Caves and Barton 1990; Nickell 1996; Acs et al. 1999; Gopinath et al. 2004).

Two recent empirical studies examine the links between industrial structure and external economies directly. Feser (2002) includes the level of structural concentration in the manufacturing sector as a control in an establishment-level productivity analysis of spatially attenuating sources of agglomeration economies in two manufacturing sub-industries, finding a strong positive relationship between a competitive structure (lower concentration) and productivity in an innovation-intensive industry (measuring and controlling devices) but no significant association for a less technology-driven industry (farm and garden equipment). Rosenthal and Strange (2003) use micro-level data to calculate indicators of structure, regional 
cross-industry diversity, and concentric ring measures of localization and urbanization economies for six industries. They find that a higher share of regional industry employment in smaller establishments (or lower structural concentration, which they describe as an "entrepreneurial industrial system") is associated with more firm births and new-establishment employment. Both of these studies reveal a link between regional industrial structure concentration and economic outcomes. Yet Feser does not study industry-specific structure and neither Feser nor Rosenthal and Strange examine the intervening effect that structure may have on firms' realization of specific kinds of local external economies.

The hypothesis tested in this paper is that a higher level of concentration in an industry in a region — that is, the dominance of a few large firms - limits agglomeration economies and ultimately diminishes the economic performance of some firms in that industry, especially small ones. If true, an important implication is that the distribution across local enterprises of frequently postulated benefits of clusters, districts, and other forms of agglomeration is uneven, contingent on the specific structure of the industry in the place. Again, these ideas often have been tested directly in case studies and indirectly in studies of the influence of industrial diversity and average establishment size on various measures of firm or industry performance. Our objective is to construct a test of the hypothesis that measures the concept of industryspecific structure concentration more precisely. We do that by using a combination of confidential and publicly available data to estimate the productivity effects of local structure concentration in a given study industry, of spatially varying sources of agglomeration economies for that industry, and of interactions between structure concentration and the agglomeration economy sources. In application to three industries, we find a consistently negative and substantial direct productivity effect associated with industrial structure concentration and only 
mixed and relatively weak evidence that agglomeration economies are a mediating factor in that effect.

\section{EMPIRICAL FRAMEWORK}

A substantial body of empirical work investigates regional agglomeration economies with production functions (see the discussions in Eberts and McMillen 1999; Rosenthal and Strange 2004). Research conducted through the mid-1990s typically used publicly available regional- or state-level data to estimate aggregate industry production functions for selected Standard Industrial Classification (SIC) sectors. With better availability of micro-level data, plant-level estimation has largely supplanted the aggregate approach. At the micro-level scale, better capital data are available, aggregation bias is not an issue, the assumption of profit maximization is more reasonable, and intraregional spatial variation can be better incorporated. Micro-level studies of agglomeration economies generally have found substantial positive influences on productivity, though with much variation across agglomeration economy sources, industries, and establishment sizes (Malmberg et al. 2000; Feser 2001; 2002; Rigby and Essletzbichler 2002; Henderson 2003).

Our establishment-level production function is

$$
\begin{aligned}
\ln Q= & \alpha_{0}+\sum_{i} \alpha_{i} \ln X_{i}+\frac{1}{2} \sum_{i} \sum_{j} \beta_{i j}\left(\ln X_{i} \ln X_{j}\right) \\
& +\sum_{k} \gamma_{k} \ln Z_{k}+\sum_{i} \sum_{k} \mathrm{I}(i, k) \lambda_{i k} \ln X_{i} \ln Z_{k}+\sum_{k} \sum_{l} \mathrm{I}(k, l) \lambda_{k l} \ln Z_{k} \ln Z_{l}
\end{aligned}
$$

where $Q$ is establishment output; $X$ represents four conventional inputs (capital, labor, energy, and materials); $Z$ is a vector of regional economic characteristics including industry-specific structure concentration and agglomeration economies; $i$ and $j$ index the inputs in $X$; and $k$ and $l$ index the components of $Z$. The two indicator functions permit selective inclusion of interaction terms: the first allows the variables in $Z$ to enter the production function in factor-augmenting 
form; the second permits the square of structure concentration to be an independent variable and enables estimation of the indirect effect of concentration on productivity via agglomeration economy sources. The translog form of (1) avoids imposing strong a priori assumptions such as constant returns to scale. Following the inverse demand function methodology of Kim (1992), we jointly estimate cost share equations derived from first-order conditions, improving efficiency. The details of the cost share derivations are provided in Appendix A.

All non-dummy variables are mean-centered. Variables not measured as percentages or ratios are transformed with natural logarithms; the coefficient estimates are interpreted as elasticities at the sample means. Additive disturbance terms appended to the production function and cost share equations are assumed to follow a multivariate standard normal distribution. One cost share equation (energy) is dropped to avoid a singular covariance matrix and the system is estimated using iterated nonlinear seemingly unrelated regression (Zellner efficient estimation), allowing disturbances to be correlated across equations. The estimates are asymptotically equivalent to maximum likelihood estimates and are invariant to the choice of which cost share equation to omit (Greene 2003).

We study three manufacturing industries chosen to satisfy several criteria: plastics and rubber (SIC 30), metalworking machinery (SIC 354), and measuring and controlling devices (SIC 382). Each has enough establishments spread across regions to present adequate variation in regional industrial structure concentration and sufficient observations to support the translog estimation system. The industries are flexible in location choice, relatively homogeneous in production technology, and contrast two traditional industries producing standardized products in a capital-intensive manner with a more technology-intensive industry (measuring and controlling devices) subject to shorter innovation cycles. The geographic regions are U.S. Department of 
Agriculture Labor Market Areas (LMAs) (2003), which approximate functional economic areas and cover the contiguous 48 states.

\section{DATA AND VARIABLE CONSTRUCTION}

The principal data are confidential establishment-level records from the Census of Manufactures for 1992, 1997, and 2002, compiled in the Longitudinal Research Database (LRD) of the U.S. Census Bureau. We combine public data with conventional input, output, and cost share measures constructed from the LRD to create establishment- and regional-level indicator and control variables. Appendix B provides details.

The LRD includes entries for all manufacturing establishments in the country, but the smallest stand-alone establishments (typically with five or fewer employees) are exempt from some filing requirements and their records contain information imputed from industry averages. We exclude these "administrative records" to avoid interpreting imputation rules rather than productivity relationships (Feser 2001; Henderson 2003). We omit plants with non-positive employment, output, inputs, or cost shares, and all establishments in Alaska, Hawaii and central New York, Los Angeles, and Chicago, because of those regions' unusual isolation or density and volume of international linkages.

Given that we have access to three years of LRD data, a panel study would appear to be the most appropriate and advantageous approach, yet we estimate the models as cross-sections. The reason is that LRD-constructed balanced panels severely curtail the number of observations and skew samples toward large, established firms (Olley and Pakes 1996; Henderson 2003); combining years into a panel requires excluding plants that do not appear in the same industry and region in successive Census years due to changes such as firm births, deaths, relocations, and switches in primary industry. Such panels reduce the spatial variation that is of particular 
interest here in regard to both regional industrial structure concentration and agglomeration economies. Our approach is not without costs. We discuss the implications for the issue of selfselection below.

Measuring Regional Industrial Structure Concentration. The concept of regional industrial structure concentration has not appeared in quantitative empirical research so no widely agreed-upon measure exists. Previous work conducted at the industry scale has adopted a variety of indicators for industrial structure or market power, including concentration ratios, likelihood ratios, inequality indices, entropy measures, and sample firm size variance (Amato 1995; Powell and Lloyd 2005). Although empirical comparisons suggest that no single measure is superior, the concentration ratio is the most widely used, in part because concentration ratios are available from the Census at the national level in public-release versions of the Census of Manufactures (Golan et al. 1996).

We calculate regional industrial structure concentration as a five-firm concentration ratio: the percentage of total regional industry shipment value accounted for by the five largest ("dominator") firms. The concentration ratio measure is advantageous because it is relatively insensitive to the small end of the size distribution, which is appropriate given our necessary omission of the smallest plants. Establishments are aggregated to firms based on the sameindustry, same-region manufacturing components of multi-unit firms. We include administrative records for this purpose since all establishments report shipment values. Regional industrial structure concentration is only a meaningful concept in situations in which "dominant" firms are distinguished from a larger set of "non-dominant" plants, so we exclude regions containing fewer than twelve firms in the study industry. For the purpose of modeling the effect of industry structure among different kinds of producers, we identify a smaller subset of "dominated" 
establishments - those belonging to firms reporting less than one tenth the shipment value of the smallest dominator firm - from among the mix of non-dominant plants in a place.

Sources of Agglomeration Economies. Our production model includes measures of labor pools, input and supply pools, and knowledge spillover sources, calculated for each establishment in the sample. The variables, which characterize potential agglomeration economies based on observable characteristics, are conceptually similar to measures employed in other research (Feser 2002; Rigby and Essletzbichler 2002; Koo 2005b; Renski 2006).

The LRD provides establishment locations by county, enabling us to account for the intraregional spatial attenuation of agglomeration influences with distance. Distance decay is modeled with an exponential term $d^{-\alpha}$, where $d$ is distance and $\alpha$ is a variable parameter, as is the absolute cutoff distance (Anselin 2002). We tested alternative decay parameters empirically, finding that a slow decay $(\alpha=0.1)$ provided the best fit for the less spatially concentrated rubber and plastics and metalworking machinery industries and a much steeper decay $(\alpha=1)$ a better fit the more spatially concentrated measuring and controlling devices industry.

Labor pooling is measured as an establishment's access to workers with skills that roughly match the industry's expected occupational requirements:

$$
A L_{k x}=\sum_{c}\left(\frac{O_{c x}}{O_{c T}} d_{c k}{ }^{-\alpha}\right)
$$

where $x$ is the study industry, $c$ indexes counties, $k$ is the target establishment's county, $O_{c x}$ is county c's residential workforce in the top 15 occupations employed by industry $x$ nationally, $O_{c T}$ is county $c$ 's total workforce, and $d_{c k}$ is the distance between the centroids of county $c$ and the county of the target establishment for distances up to 75 miles and zero otherwise. 
Potential supply pools of manufactured inputs and producer services are calculated by weighting the local presence of supplier industries by the importance of each industry as a supplier to the study industry at the national level. Manufacturing input supply pooling is:

$$
A I_{k x}=\sum_{c}\left(\left(\sum_{m} \frac{E_{c m} P_{x m}}{P_{x M}}\right) \cdot d_{c k}{ }^{-\alpha}\right)
$$

where $m$ indexes manufacturing industries, $E_{c m}$ is county $c$ 's employment in industry $m, P_{x m}$ is the dollar amount that the study industry purchases nationally from supplier industry $m, P_{x M}$ is the study industry's total national purchases from the manufacturing sector, and the other notations are the same as for labor pooling. Producer services pooling has nearly the same formula except that purchases and local employment refer to suppliers of producer services:

$$
A S_{k x}=\sum_{c}\left(\left(\sum_{s} \frac{E_{c s} P_{x s}}{P_{x S}}\right) \cdot d_{c k}{ }^{-\alpha}\right)
$$

where $s$ indexes producer services industries and $P_{x S}$ is the study industry's total national purchases of producer services.

Sources of knowledge spillovers are typically measured with input indicators such as university research expenditures and the density of employment of scientists and engineers, or outcome indicators such as patents or new inventions (Jaffe et al. 1993; Koo 2005b). Since the labor pooling measure already accounts for the spatial concentration of scientists and engineers, we use two variables to indicate other sources of knowledge spillovers. The first gauges regional access to relevant basic research and knowledge:

$$
A R_{k x}=\sum_{c}\left(\left(\sum_{f} E X P_{c f}\right) \cdot d_{c k}^{-\alpha}\right)
$$

where $f$ indexes industry-relevant academic fields, $E X P_{c f}$ is the total amount of research expenditures in academic field $f$ during the previous five years at research universities located in 
county $c$, and the other variables are as described above. The maximum distance is set at 200 miles, since university-industry interactions generally need to occur less frequently than labor and supply interactions to impact firm practices (Tornatzky and Fleischer 1990).

The second measure uses patents to indicate private sector research activity and regional innovative culture. Although patents are an imperfect proxy for innovative activity, they are related to the market value of knowledge and there are few viable alternatives (Jaffe et al. 1993; Sampat et al. 2003). The measure weights the volume of patents in each technology classification by the relative importance of those technology categories to the target industry:

$$
A P_{r x}=\sum_{g \in K}\left(\frac{P A T_{g r}}{P O P_{r}} N_{g x}\right)
$$

where $g$ indexes patent technology classifications, $r$ signifies the region, $x$ represents the study industry, $K$ is the set of patent technology classifications relevant to the study industry (both directly and via cross-industry spillovers), $P A T_{g r}$ is the number of utility patents granted within region $r$ in the last five years in patent technology class $g, P O P_{r}$ is the regional residential population, and $N_{g x}$ is a relevance index developed from citation flows (Koo 2005a). Unlike the other agglomeration variables, the patenting measure incorporates geography solely by region.

Additional Controls. We use dummy variables for Census Regions to control for different macro-regional levels of development and macroeconomic conditions. Regional unemployment rates and median household income levels capture local economic conditions, and population density helps control for regional size, level of resources, and the absolute dimension of potential agglomeration economies, as well as urban congestion and other agglomeration diseconomies. A regional Herfindahl-Hirschman index calculated across fourdigit SIC industries measures regional industrial diversity (inversely), controlling for "Jacobs externalities" or spillovers that occur across industries (Glaeser et al. 1992). The changes in 
regional industrial structure concentration and diversity from twenty years prior to the model year distinguish cumulative or persistent effects.

\section{SELECTION AND VALIDITY}

Endogeneity arising from self-selection is a validity threat in research that examines agglomeration economies through production outcomes. The firms that are the most productive for unobserved reasons may also be those that are best at identifying productivity-enhancing locations. This possible location selectivity suggests that agglomeration variables may be endogenous in the production function (Hanson 2001; Henderson 2003; Graham and Kim 2008). This is a particular case of the more general issue of possible endogeneity or simultaneity in firm selection of inputs.

There are two statistical approaches taken in the literature to address endogeneity: instrumentation and fixed effects. Henderson (2003) attempts both in an application using LRD data. Because there are no suitable instruments available for plant-specific variables, industry scale, or agglomeration economies at the regional level, he tests exogenous metropolitan attributes such as county air quality attainment status and market potential, finding that those variables are too weak as instruments for agglomeration economies to produce useful results. That leads him to implement a fixed effects approach by including time-invariant dummies for plant locations. (He also reports unsatisfactory results from experiments with time-specific dummies). This method fails to solve the endogeneity issue, however, to the degree that the presence of a plant in a particular location and time results from a profit-maximizing choice (Rosenthal and Strange 2004).

Unfortunately, neither instrumentation nor fixed effects are usable in this research. Input prices are the standard choice as instruments (Ackerberg et al. 2005), but are not applicable to 
agglomeration economies. Even ignoring intraregional variation, there are no effective instruments available for specific sources of agglomeration economies at the regional scale. Incorporating time fixed effects requires constructing a balanced panel dataset, thus excluding plants that do not appear in each year of the panel and reducing spatial variation dramatically, as noted above. Location fixed effects, on the other hand, mask the impacts of independent variables that are spatially rather than temporally variant, eliminating the variation in plant size and location that constitutes the rationale for this research. Consequently, the relevant question is whether self-selection bias is likely to be significant enough to invalidate our results.

We think two considerations moderate the validity threat posed by self-selection. First, recent empirical work suggests that distortions arising from endogeneity are typically small and are as likely to understate as overstate the influence of agglomeration. For instance, Henderson (2003) finds the estimated impacts of agglomeration economies on productivity actually increase when plant fixed effects are added. In Rice et al. (2006), switching to an instrumental variables model from ordinary least squares yields slightly larger coefficients and directionally similar results. Using the LRD, Ellison et al. (2010) find that their principal results regarding coagglomeration are robust to the instrumental variables approach. Koo and Lall (2007) test location selectivity bias in selected Indian manufacturing industries by employing a two-stage Heckman sample selection model. The correction factor from the first stage is statistically significant for the majority of industries, and the effects of agglomeration economies do tend to be overstated in the simple production function estimation compared to the two-stage model. Yet the agglomeration parameters are not distorted very much: none that are overestimated in the simple production model fall outside of the 95 percent confidence interval of the corresponding estimate from the two-stage model, and the rank-order of agglomeration economy 
effects is identical. Finally, Puga et al. (2007) demonstrate that the distribution of firm productivity across French cities is consistent with an agglomeration rather than a selection mechanism.

Second, small manufacturing plants that may be impacted by a regionally concentrated industrial structure lack market power and are somewhat more constrained in location choice than larger establishments, especially in an interregional context (i.e., they tend to be less footloose).

Ultimately, we employ cross-sectional analysis despite the endogeneity issue not only because of evidence that any bias is likely to be small, but also because there are no alternative approaches that permit us to investigate the research questions satisfactorily with the data we have available. In favoring fixed effects approaches to address the selection problem, recent empirical research downplays the firm size and spatial variation issues that we contend are also important. When we constructed panels for each study industry to investigate the possibility of a panel estimation approach, the numbers of observations were reduced by no less than 30 and as much as 55 percent depending on the industry and year. As expected, samples were heavily skewed, with the remaining plants substantially larger (employment averaging about 25 percent greater) and concentrated in fewer regions. We believe that the empirical importance of endogeneity may be overstated in the literature, leading researchers to employ econometric solutions that introduce other validity threats. Nevertheless, the possibility of self-selection bias should be weighed in considering and interpreting the findings presented below.

\section{DESCRIPTIVES}

Table 1 reports the number of establishments in the U.S. industries and the study samples, with the differences mainly due to excluded administrative records. Sample 
establishments tend to be larger than overall industry averages, a reminder that the analysis does not include the very smallest manufacturers. Regional "dominator" establishments average three to four times the size of the typical plant and ten to thirty times the size of "dominated" plants, depending on whether employment or shipments is used as the barometer of size. Increases in mean establishment sizes and the fraction of establishments in dominator firms reflect consolidation in the manufacturing sector. All three study industries are spatially concentrated, with most plants located in metropolitan areas. The metro-heavy distribution is exaggerated by excluding regions with fewer than twelve industry firms, yet even overall the study industries are mainly found in metropolitan counties.

The largest share of production costs in the rubber and plastics industry is materials expenditures (see Table 2). Labor costs predominate in metalworking machinery plants (Table 3), and measuring and controlling device manufacturers spend slightly more on labor than materials, with those two inputs constituting most of production costs in that industry (Table 4). These observations suggest that labor pooling advantages might be more important in the metalworking machinery and measuring and controlling devices industries than for rubber and plastics manufacturing. Knowledge spillovers may be most influential in higher technology industries; measuring and controlling device plants tend to be located in regions with much greater average patenting rates than the other study industries.

The five agglomeration economy variables are positively correlated with each other, as expected, but possess sufficient independent variation for regression analysis (see Table 5). The correlations between the two supply pooling measures are moderately high for all three industries (between 0.62 and 0.77 ) and consequently the estimated coefficients should be evaluated with some caution. Regional industrial structure concentration is negatively correlated 
with most of the agglomeration economy variables; larger and denser regions provide more potential agglomeration economies and are also less likely to be dominated by a few firms.

\section{RESULTS}

We estimate equation (1) and the three associated cost share equations separately for each of the nine cross-sections defined by the three study industries and three years of data. The results are reported in Tables 6-8. Histograms and normal quantile plots confirm the approximate normality of the residuals. Alternative starting values used to test model convergence demonstrate that the optima are robust within a considerable domain. BreuschPagan tests are mixed, but use of heteroskedasticity-corrected standard errors (reported in Tables 6-8) did not alter the substantive results in any case. Monotonicity and convexity are satisfied in the vicinity of the point of approximation but caution is warranted in applying the results to distant points in the sample space. We tested and rejected commonly applied model simplifications (Drucker and Feser 2007). ${ }^{2}$ As is standard in cross-sectional work, we interpret the final estimated parameters as representing a long-run equilibrium.

Conventional Inputs and Control Variables. The coefficients of the conventional inputs and cross-terms have expected signs: production is positively related to input quantities, and negative cross-products reveal input substitution in each model. Population density has positive effects on productivity in eight models, reaching conventional significance levels in five, suggesting that urbanization economies usually outweigh congestion and other diseconomies of density. The magnitude of the influence is quite small in practical terms. It would require an increase in population density of more than 13 percent to raise average output by one percent for

2 Tests strongly reject homotheticity, homogeneity, and constant returns to scale in production, Hicks neutrality for the industrial structure concentration variable, and the Cobb-Douglas functional form. The constant elasticity of substitution functional form and Hicks neutrality for the agglomeration variables also are rejected, somewhat less strongly. 
measuring and controlling devices plants in 2002, and even greater increases in the other models. $^{3}$

There is much variability in the influence of income, unemployment, industrial diversity, and the macro-regional dummy variables. Higher regional median household incomes are associated with higher productivity in the rubber and plastics industry, where income may indicate local workforce skills, but with lower productivity in the other two study industries. Labor's average share of production cost is larger for metalworking machinery and measuring and controlling device establishments, so higher wage costs may outweigh skill advantages. Differing macroeconomic conditions may partially explain the variation in the effect of unemployment over time, but the unevenness across industries indicates industry-specific associations with establishment-level production.

The estimated coefficients of industrial diversity are significant and negative in the measuring and controlling devices and metalworking machinery industries, suggesting Jacobs externality benefits from cross-industry knowledge or technology spillovers (recall that the measure of industrial diversity is inverted). The influence is small: a standard deviation increase in industrial diversity from the sample mean is associated with higher output of about four percent in the model with the largest coefficient. Diversity is not significant in the rubber and plastics industry models. The difference across the study industries is consistent with an industry lifecycle interpretation: technology- and innovation-intensive industries benefit from diversity of thought and spillovers across industries whereas the traditional manufacturing industry benefits from targeting local resources toward a restricted set of regional strengths. The effects of the change in diversity from the historic period to the sample year are negligible.

\footnotetext{
3 The weakness of the influence likely is at least partially due to the omission of the nation's three most populous city centers.
} 
Agglomeration Economies. The effects of regional labor pools are small and vary by year for each industry. For measuring and controlling devices in 1992, a two percent rise (roughly a standard deviation) in the labor pooling measure is associated with a 2.7 percent increase in output. The figure drops to less than one percent in 1997 and becomes negative in 2002. For metalworking machinery, two of the sample years show negative productivity impacts. Rubber and plastics plants benefit from labor pooling potential in 1992 and 2002, but in 1997 the effect is negligible. Labor pooling is the only agglomeration economy measured on a relative rather than an absolute scale; its influence may be captured to some degree by the sizesensitive agglomeration variables and population density.

Supply pooling demonstrates few discernible and unambiguous impacts on production. The estimated coefficients are rarely large enough to be important and in most of the models the coefficients of the two supply pooling variables are of opposite sign. Since the two variables are substantially positively correlated, it is likely that the colinearity between these two variables obscures the individual effects on production.

We obtained more interesting results for the two knowledge spillover variables.

Rubber and plastics plants in regions with greater local patenting are more productive than plants in less innovative regions. The effects are large enough to be important. In 1997 and 2002, a doubling of the regional patent rate in relevant technology fields is associated with two percent higher output. The estimated coefficient in 1992 is approximately one eighth as large, perhaps indicating that the industry has only begun to benefit substantially from private sector innovation in the last fifteen years or so, or it could result from changing assignment propensities for patent technology classifications. The estimated effects are larger for the other two study industries. In 1992, the productivity gain to metalworking machinery establishments from doubling regional 
patenting is just shy of eight percent; in 2002 the figure is over ten percent. The corresponding impact in the measuring and controlling devices industry has trended downward, from nine percent in 1992 to six percent in 2002. Even considering the smallest of these estimates, the influence of regional private sector innovation is strong enough to suggest a possible route for local or regional policy measures to influence productivity.

Location proximate to academic research expenditures in relevant fields has a much smaller impact on production than the patenting rate. In two of the metalworking machinery models, local academic research is actually a negative factor. Academic research yields a notable productivity benefit only for measuring and controlling devices plants: doubling the index of nearby academic research raises output by one to two percent. Higher technology industries, in this study represented by the measuring and controlling devices sector, may have more to gain from localized knowledge spillovers of basic research. It is also possible that the academic research indicator is capturing higher local land or employment costs, a factor that varies less across the samples of measuring and controlling device manufacturing establishments, given that they are located primarily in dense and urban counties with a university presence. The relatively small influence of academic research recorded in these models is not entirely unexpected, as the impacts of basic research are realized largely in the very long term and the variable tracks only one of many means by which universities influence regional economic performance.

Regional Industrial Structure Concentration. Higher structure concentration in the industry is a significant negative influence on establishment-level productivity. In the metalworking machinery manufacturing industry, a rise of 20 percent (approximately one standard deviation) in the total industry shipment value accounted for by the top five firms in an 
LMA is associated with a two percent decline in output at the sample means in 1992, and four percent in 1997 and 2002. The impact is greater for measuring and controlling device manufacturers: a 20 percent higher concentration ratio yields seven percent lower production in 1992 and five percent lower in 1997. The estimated coefficient of concentration is positive but insignificant in 2002. The rubber and plastics industry evidences smaller but still substantial effects from industrial structure concentration: about 1.0 to 1.3 percent lower output levels are associated with a 20 percent higher concentration ratio. These observations evaluate part of our hypothesis: all else being equal, manufacturing plants are less productive in regions in which the industry's local structure is dominated by large firms.

Because the production function includes dummy variables for relatively large and small firms in a regional industry, the coefficients of the regional industrial structure concentration measure do not simply reflect dominators outperforming locally dominated enterprises. A concentrated local industrial structure influences the production of a plant independently of that plant's status as part of a dominator or a dominated firm. In all nine industry-year samples, dominator establishments outperform, and dominated plants underperform, the sample averages by substantial margins: dominators enjoy a 14 to 28 percent productivity advantage depending on the industry and year, whereas dominated plants suffer a production deficit of similar magnitude. In each model, whether a plant belongs to a dominator firm, a dominated firm, or neither is the single strongest influence on output other than input quantities. These impactsboth the direction and the scale-make sense. Dominator firms have many resources at their disposal and can take advantage of internal economies of scale while dominated firms have access to fewer resources and internal economies of scale than the average establishment. In the cross-sectional modeling context, the causal direction of the effects indicated by the dummy 
variables is ambiguous; dominant firms may have achieved their relative size due to unobserved firm-specific efficiencies.

The influence of industry structure on establishment productivity appears to be primarily a current phenomenon. The estimated coefficients of the historic structure concentration term are mostly insignificant and small in comparison to the typical twenty-year change in the concentration ratio. Omitting the historic concentration variable changes the current concentration coefficients little. The minimal influence of historic concentration is reasonable given the changes in industry composition, products and production technologies, and national economic conditions over the intervening period.

The figures discussed in the preceding paragraphs are direct effects, equal to the marginal effects of regional industrial structure concentration evaluated at the sample means of the independent variables. Industrial structure concentration, however, enters the production function nonlinearly, with a quadratic term and interactions with both the conventional input and agglomeration economy variables. Therefore the estimated marginal effects of industrial structure vary with the levels of inputs and potential agglomeration economies and with the base level of concentration. The nonlinearities modeled in this way are simple, just an increasing or decreasing trend in relation to the interacted variable. For instance, in the rubber and plastics industry, and for the measuring and controlling devices industry in 2002 , the coefficient of the square of concentration is large and negative, so that the negative impact of industrial structure concentration on performance increases as the level of concentration rises. The opposite holds in 1992 and 1997 for both the metalworking machinery and the measuring and controlling devices industries: the positive concentration-squared term indicates that the deleterious effects of 
industrial structure concentration on production are felt most acutely in those regions with moderate levels of concentration.

The interaction terms between industrial structure concentration and the conventional inputs specify how the marginal effects of concentration on productivity change with input quantity, and provide additional insight into the role of plant size. Because the estimation point for the model system is at the sample means and the results become less reliable moving away from this point, we interpret the variation in the effects of industrial structure qualitatively. For example, in the 2002 rubber and plastics model, the effects of regional industrial structure concentration are small but negative at the sample means as indicated by the coefficient of the concentration variable). The interaction terms between concentration and capital, labor, energy, and materials are all positive, so that plants using greater quantities of the four conventional inputs experience more positive effects of concentration. In other words, a concentrated industrial structure acts as more of a hindrance to the productivity of smaller rubber and plastics plants. Establishments with sufficiently large throughput even benefit in terms of productivity from a more concentrated industrial structure in their regions. This pattern is replicated for most of the industry-year models: the interaction terms imply that the marginal effect of concentration is greater in magnitude (a larger negative number) for smaller plants. (At this point, it is worth reiterating that none of the models include the very smallest plants, usually with five or fewer employees, which are exempted from full Census reporting requirements.) Three of the models (1997 rubber and plastics, 1992 metalworking machinery, and 2002 measuring and controlling devices) produce a balanced mix of positive and negative interaction terms, and the effect of industrial structure concentration remains relatively stable as quantities of the four inputs grow or shrink together. 
The primary interest of this study is how the estimated impacts of regional industrial structure concentration vary with potential agglomeration economies. In rubber and plastics and measuring and controlling devices in 2002, negative interaction terms that are of sizable magnitude in comparison to the agglomeration measures show that concentration has positive productivity effects in regions with few available agglomeration economies and negative effects where the levels of agglomeration economies are large. A concentrated industry structure may hinder local establishments from accessing agglomeration economies, thus lowering productivity below expectations primarily in regions offering greater potential agglomeration benefits. Locally dominant firms in areas lacking agglomeration economies may create alternative advantages through local economic power that then spill over to smaller firms. For most of the models, however, the concentration-agglomeration interaction terms are a mix of positive and negative values. Since the sources of agglomeration economies co-vary across regions, these models describe little difference in the impact of industrial structure concentration by agglomeration regime. Together with the observations pertaining to the direct impacts of agglomeration economies, we have the evidence we need to evaluate our hypothesis. For the majority of study industries and years, it does not seem to be the case that small establishments in industries with a concentrated structure are less productive because they cannot realize benefits from potential agglomeration economies. Industrial structure concentration appears to reduce establishment-level productivity in our study industries, but not by restricting the ability of manufacturers to access local benefits of agglomeration.

Sensitivity Checks. We performed a variety of tests to gauge the robustness of our results. We tested numerous substitute measures of regional industrial structure, including concentration ratios with different numbers of firms in the numerator, concentration ratios based 
on shipment values instead of employment, and indices calculated upon the full firm size distribution. Selected estimation outcomes are detailed in Drucker (2007). Altering the minimum number of firms in a regional industry for inclusion from twelve to as few as six and as large as fifty changes the goodness of fit of the estimations and the significance of individual variables but not the qualitative interpretations of the results obtained. Dummy variables that classify dominated plants by establishment employment or firm shipment value rather than firm employment generate much the same outcomes. If establishments located in the central LMAs of New York, Los Angeles, and Chicago are included in the samples, or if the central LMAs associated with the ten most populous cities are excluded, the influence of industrial structure is nearly identical, though there are some small changes in the parameters on the agglomeration economy variables. Regarding the flexible parameters of the agglomeration economy variables, the results presented here are largely robust to varying distance decay specifications (Drucker 2007).

\section{CONCLUSION}

We find that although a concentrated regional industrial structure is directly associated with lower productivity in our study sectors, particularly for small manufacturing establishments, it does not appear to limit access to sources of agglomeration economies in those industries. With regard to agglomeration economy sources on their own, whereas labor and supply pools have minimal effects on output in our study industries, knowledge and information spillovers from private sector innovative activity influence production positively. Proximity to relevant academic research is associated with higher productivity among measuring and controlling device manufacturers and may influence other technology-intensive industries. To the extent that a concentrated industrial structure hinders smaller businesses, the local economy possesses 
less flexibility to react to changing economic conditions, an important implication for efforts to model variations in regional growth and adjustment. Our study, albeit restricted to three industries, generates evidence that agglomeration economies are not an important mediating mechanism for the productivity effect associated with local industry structure. Further study is warranted to investigate other explanations. 


\section{APPENDIX A: Derivation of Production Function System.}

Following Kim (1992), we derive cost share equations from standard first-order conditions representing profit maximization. Let the production function be expressed generally as:

$$
Q=g(Z) \cdot f(X)
$$

where $Q$ is firm output, $X$ is a vector of conventional inputs, and $Z$ is a vector of other relevant regional characteristics. The firm then seeks to maximize the profit function

$$
\Pi=\frac{\partial C}{\partial Q} Q-\sum_{i} P_{i} X_{i}
$$

where $\Pi$ is total profits, $\partial C / \partial Q$ is the marginal cost of output, and $P_{i}$ is the input price of the $\mathrm{i}^{\text {th }}$ input $X_{i}$. Given that the production function satisfies the typical regularity conditions, and that input markets are competitive, the first-order condition for profit maximization states that

$$
\frac{\partial \Pi}{\partial X_{i}}=\frac{\partial C}{\partial Q} \cdot \frac{\partial Q}{\partial X_{i}}-P_{i}=0
$$

for each input $X_{i}$, and, rearranging,

$$
\frac{\partial Q}{\partial X_{i}}=\frac{P_{i}}{\partial C / \partial Q}=\lambda P_{i}
$$

where $\lambda$ is a Lagrange multiplier that is the reciprocal of the marginal cost of output. The relation expressed in equation (A4) holds for each input, so both sides may be multiplied by the $\mathrm{i}^{\text {th }}$ input quantity, $X_{i}$, and summed over the inputs to yield a multiple of the total input cost $C$ :

$$
\sum_{i} \frac{\partial Q}{\partial X_{i}} X_{i}=\lambda \sum_{i} X_{i} P_{i}=\lambda C
$$

The inverse demand function is obtained by rearranging equation (A5) and substituting into equation (A4):

$$
P_{i}=C \frac{\partial Q / \partial X_{i}}{\sum_{i}\left(\partial Q / \partial X_{i}\right) X_{i}}
$$

Rewriting (A6) in terms of logarithmic input and outputs yields

$$
P_{i}=C \frac{\left(\partial \ln Q / \partial \ln X_{i}\right)\left(Q / X_{i}\right)}{\sum_{i}\left(\partial \ln Q / \partial \ln X_{i}\right)\left(Q / X_{i}\right) X_{i}}=C \frac{\partial \ln Q / \partial \ln X_{i}}{\sum_{i}\left(\partial \ln Q / \partial \ln X_{i}\right) X_{i}} .
$$

Rearranging once again yields an equation for the cost share, $S_{i}$, for the $\mathrm{i}^{\text {th }}$ input: 


$$
S_{i} \equiv \frac{P_{i} X_{i}}{C}=\frac{\partial \ln Q / \partial \ln X_{i}}{\sum_{i}\left(\partial \ln Q / \partial \ln X_{i}\right)} .
$$

The logarithmic marginal products of each input are obtained by differentiating the production function in equation (1) with respect to $X_{i}$ :

$$
\begin{aligned}
\frac{\partial \ln Q}{\partial \ln X_{i}} & =\alpha_{i}+\frac{1}{2} \sum_{j} \beta_{i j} \ln X_{j}+\frac{1}{2} \sum_{j} \beta_{j i} \ln X_{j}+\sum_{k} \mathrm{I}(i, k) \lambda_{i k} \ln Z_{k} \\
& =\alpha_{i}+\sum_{j} \beta_{i j} \ln X_{j}+\sum_{k} \mathrm{I}(i, k) \lambda_{i k} \ln Z_{k}
\end{aligned} .
$$

Substituting (A9) into the formula (A8), the cost shares, $S_{i}$, for the translog production function are expressed as:

$$
S_{i}=\frac{\partial \ln Q / \partial \ln X_{i}}{\sum_{i}\left(\partial \ln Q / \partial \ln X_{i}\right)}=\frac{\alpha_{i}+\sum_{j} \beta_{i j}\left(\ln X_{j}\right)+\sum_{k} I(i, k) \lambda_{i k} \ln Z_{k}}{\sum_{i}\left(\alpha_{i}+\sum_{j} \beta_{i j}\left(\ln X_{j}\right)+\sum_{k} I(i, k) \lambda_{i k} \ln Z_{k}\right)} .
$$

The only assumptions required for this derivation are the production function regularity conditions, firm-level profit maximization, and competitive input markets. The approach is implemented in an agglomeration economies context by Feser (2002).

\section{APPENDIX B: Variable Construction.}

Units. Monetary values are thousands of nominal dollars. Time measures are thousands of hours.

Inputs and Output. Variables are calculated at the establishment level. Output $(Q)$ is the total value of shipments adjusted for inventories and work in progress:

$$
Q=T V S+(W I E-W I B)+(F I E-F I B) .
$$

TVS is the total value of shipments; WIE and WIB are work in progress at the end and beginning of the year; FIE and $F I B$ are end-of-year and beginning-of-year finished product inventories.

Capital is constructed using gross stocks instead of perpetual inventory methods that require longitudinal plant-specific observations. Stock measures perform well in micro-level 
research using the LRD (Doms 1996; Dwyer 1997). Capital $(K)$ is the sum of end-of-year capital assets and capitalized building and machinery rental expenditures:

$$
K=T A E+\frac{B R}{B P R}+\frac{M R}{M P R}
$$

$T A E$ is total end-of-year building and machinery assets; $B R$ is building rental expenditures; $M R$ is machinery rental expenditures; $B P R$ and $M P R$ are (unpublished) annual national 3-digit-SIC capital prices obtained from the Bureau of Labor Statistics averaged across asset categories.

Labor $(L)$ is production-worker-equivalent hours, derived as the ratio of total wages to production worker average hourly wages:

$$
L=\frac{W P+W N P}{(W P / P H)}
$$

$W P$ and $W N P$ are production and non-production payrolls; $P H$ is production worker hours.

Energy $(E)$ is the sum of purchased electricity and fuel quantities:

$$
E=C F\left(\frac{1,000}{E P R}\right)+P E\left(\frac{3,412.705}{1,000}\right) .
$$

$P E$ is millions of British Thermal Units of purchased electricity; $C F$ is purchased fuels cost; $E P R$ is the average state-level industry-specific energy price from the U.S. Energy Information Administration State Energy Data System.

Materials $(M)$ is the total cost of materials, parts, contract work, resales, purchased services, and repairs, adjusted for changes in materials inventories:

$$
M=C P+C R+C W+C P C+R B+R M+(M I B-M I E) .
$$

$C P$ is materials and parts cost; $C R$ is expenditures for resales; $C W$ is contract work costs; $C P C$ is purchased communications services; $R B$ and $R M$ are building and machinery repairs; $M I B-M I E$ is the difference between beginning- and end-of-year materials inventories. 
Capital costs are total capital assets adjusted by multiplying by (unpublished) Bureau of Labor Statistics capital asset prices and LRD-reported building and machinery rental costs. Labor costs are total wages and salaries plus supplemental labor expenditures. Energy costs are purchased electricity and fuels costs. Materials costs are identical to the quantity measure.

Agglomeration Economies. Labor pooling: the top 15 occupations for each industry are identified from the Bureau of Labor Statistics national staffing matrix. Values of $O_{c}$ and $O_{T c}$ are from the 1990 and 2000 Census Equal Employment Opportunity tabulations. Supply pooling: purchasing amounts are from the Make and Use tables of the Benchmark Input-Output Accounts from the Bureau of Economic Analysis. $E_{c m}$ and $E_{c s}$ are tabulated from the Longitudinal Business Database (LBD), another confidential establishment-level Census dataset that covers most economic sectors but lacks full input and output information. Knowledge spillovers: the academic fields relevant to each industry are modified from Cohen et al. (2002). Annual university research expenditures are from the National Science Foundation's CASPAR database. Patent counts are from the CASSIS bibliographic system of the U.S. Patent and Trademark Office (USPTO). Industry-relevant patent technology classifications are identified from the USPTO technology-industry match and a technology flow matrix developed by Koo (2005a).

Control Variables. Regional unemployment rates, household incomes, and population densities are constructed for LMAs by combining county-level estimates. Unemployment rates are from the Bureau of Labor Statistics Local Area Unemployment Statistics. Median household income levels are from Census Small Area Income and Poverty Estimates. Population density is calculated from Census population estimates. Establishment-level data from the LBD are used to construct the regional industrial diversity and historic diversity measures. Because the LBD starts in 1977, the historic diversity measure for the 1992 sample is from 1977. 


\section{REFERENCES}

Ackerberg, D. A., K. Caves, and G. Frazer. 2005. Structural identification of production functions. Working Paper. University of Colorado.

Acs, Z. J., R. Morck, and B. Yeung. 1999. Productivity growth and firm size distribution. In Z. J. Acs, B. Carlsson, and C. Karlsson (eds.), Entrepreneurship, Small and Medium-Sized Enterprises and the Macroeconomy: 367-396. Cambridge, United Kingdom: Cambridge University Press.

Amato, L. 1995. The choice of structure measure in industrial economics. Quarterly Journal of Business and Economics, 34 (2): 39-52.

Anselin, L. 2002. Under the hood: Issues in the specification and interpretation of spatial regression models. Agricultural Economics, 27 (3): 247-267.

Audretsch, D. B. 2001. Research issues relating to structure, competition, and performance of small technology-based firms. Small Business Economics, 16 (1): 37-51.

Booth, D. E. 1986. Long waves and uneven regional growth. Southern Economic Journal, 53 (2): 448-460.

Carree, M., and R. Thurik. 1999. Industrial structure and economic growth. In D. B. Audretsch, and R. Thurik (eds.), Innovation, Industry Evolution, and Employment: 86-110. Cambridge, United Kingdom: Cambridge University Press.

Caves, R. E., and D. R. Barton. 1990. Efficiency in U.S. Manufacturing Industries. Cambridge: MIT Press.

Chinitz, B. 1961. Contrasts in agglomeration: New York and Pittsburgh. The American Economic Review, 51 (2): 279-289.

Cohen, W. M., R. R. Nelson, and J. P. Walsh. 2002. Links and impacts: the influence of public research on industrial R\&D. Management Science, 48 (1): 1-23.

Dissart, J. C. 2003. Regional economic diversity and regional economic stability: research results and agenda. International Regional Science Review, 26 (4): 423-446.

Doms, M. E. 1996. Estimating capital efficiency schedules within production functions. Economic Inquiry, 34 (1): 78-92.

Drucker, J. 2007. Regional dominance and industrial success: a productivity-based analysis. Doctoral Dissertation, Department of City and Regional Planning, University of North Carolina: Chapel Hill, North Carolina.

Drucker, J., and E. J. Feser. 2007. Regional industrial dominance, agglomeration economies, and manufacturing plant productivity. Working Paper CES-WP-07-31: Center for Economic Studies, United States Census Bureau.

Dwyer, D. W. 1997. Productivity races II: the issue of capital measurement. Working Paper CES-Discussion Paper-97-3: Center for Economic Studies, United States Census Bureau.

Eberts, R. W., and D. P. McMillen. 1999. Agglomeration economies and urban public infrastructure. In E. S. Mills, and P. C. Cheshire (eds.), Handbook of Regional and Urban Economics, Vol. 3: 1456-1495. Amsterdam, New York: Elsevier Science Pub. Co.

Ellison, G., E. L. Glaeser, and W. R. Kerr. 2010. What causes industry agglomeration? Evidence from coagglomeration patterns. The American Economic Review, 100 (3): 1195-1213.

Enright, M. J. 1995. Organization and coordination in geographically concentrated industries. In N. R. Lamoreau, and D. M. G. Raff (eds.), Coordination and Information: Historical 
Perspectives on the Organization of Enterprise: 103-146. Chicago, Illinois: University of Chicago Press.

Evans, A. W. 1986. Comparisons of Agglomeration: Or What Chinitz Really Said. Urban Studies, 23: 387-389.

Feser, E. J. 2001. A flexible test for agglomeration economies in two US manufacturing industries. Regional Science and Urban Economics, 31 (1): 1-19.

Feser, E. J. 2002. Tracing the sources of local external economies. Urban Studies, 39 (13): 2485-2506.

Glaeser, E. L., H. D. Kallal, J. A. Scheinkman, and A. Schleifer. 1992. Growth in cities. Journal of Political Economy, 100 (6): 1126-1152.

Glaeser, E. L., and W. R. Kerr. 2008. Local industrial conditions and entrepreneurship: how much of the spatial distribution can we explain? Working Paper 09-055: Harvard Business School.

Glaeser, E. L., W. R. Kerr, and G. A. M. Ponzetto. 2009. Clusters of entrepreneurship. Working Paper 09-055: Harvard Business School.

Golan, A., G. Judge, and J. M. Perloff. 1996. Estimating the size distribution of firms using government summary statistics. The Journal of Industrial Economics, 44 (1): 69-80.

Gopinath, M., D. Pick, and Y. Li. 2004. An empirical analysis of productivity growth and industrial concentration in US manufacturing. Applied Economics, 36 (1): 1-17.

Graham, D. J., and H. Y. Kim. 2008. An empirical analytical framework for agglomeration economies. Annals of Regional Science, 42 (2): 267-289.

Greene, W. H. 2003. Econometric Analysis. 5th Ed. Upper Saddle River, New Jersey: Prentice Hall.

Hanson, G. H. 2001. Scale economies and the geographic concentration of industry. Journal of Economic Geography, 1 (3): 255-276.

Henderson, J. V. 2003. Marshall's scale economies. Journal of Urban Economics, 53 (1): 128.

Henderson, J. V., Z. Shalizi, and A. J. Venables. 2001. Geography and development. Journal of Economic Geography, 1 (1): 81-105.

Jaffe, A. B., M. Trajtenberg, and R. Henderson. 1993. Geographic localization of knowledge spillovers as evidenced by patent citations. Quarterly Journal of Economics, 108: 577598.

Kim, H. Y. 1992. The translog production function and variable returns to scale. The Review of Economics and Statistics, 74: 546-551.

Koo, J. 2005a. Knowledge-based industry clusters: evidenced by geographical patterns of patents in manufacturing. Urban Studies, 42 (9): 1487-1505.

Koo, J. 2005b. Agglomeration and spillovers in a simultaneous framework. Annals of Regional Science, 39 (1): 35-47.

Malmberg, A., B. Malmberg, and P. Lundequist. 2000. Agglomeration and firm performance: economies of scale, localisation, and urbanisation among Swedish export firms. Environment and Planning A, 32 (2): 305-321.

Malmberg, A., and P. Maskell. 2002. The elusive concept of localization economies: towards a knowledge-based theory of spatial clustering. Environment and Planning A, 34 (3): 429449.

Nelson, R. R., and S. G. Winter. 1982. An Evolutionary Theory of Economic Change. Cambridge, MA: Harvard University Press. 
Nickell, S. J. 1996. Competition and corporate performance. Journal of Political Economy, 104 (4): 724-746.

Olley, G. S., and A. Pakes. 1996. The dynamics of productivity in the telecommunications equipment industry. Econometrica, 64 (6): 1263-1297.

Porter, M. E. 1998. Clusters and the new economics of competition. Harvard Business Review, (November/December): 77-90.

Powell, T. C., and C. J. Lloyd. 2005. Toward a general theory of competitive dominance: Comments and extensions on Powell (2003). Strategic Management Journal, 26 (4): 385-394.

Puga, D., P.-P. Combes, G. Duranton, L. Gobillon, and S. Roux. 2007. The productivity advantages of large cities: distinguishing agglomeration from firm selection. Working Paper.

Quigley, J. M. 1998. Urban diversity and economic growth. Journal of Economic Perspectives, $12(2): 127-138$.

Rantisi, N. M. 2002. The competitive foundations of localized learning and innovation: the case of the women's garment production in New York City. Economic Geography, 78 (4): 441-462.

Renski, H. 2006. An Investigation of the Industrial Ecology of Business Start-Up and Survival. Doctoral Dissertation, Department of City and Regional Planning, University of North Carolina at Chapel Hill: Chapel Hill, NC.

Rigby, D. L., and J. Essletzbichler. 2002. Agglomeration economies and productivity differences in US cities. Journal of Economic Geography, 2 (4): 407-432.

Rosenthal, S. S., and W. C. Strange. 2003. Geography, industrial organization, and agglomeration. Review of Economics and Statistics, 85 (2): 377-393.

Rosenthal, S. S., and W. S. Strange. 2004. Evidence on the Nature and Sources of Agglomeration Economies. In J. V. Henderson, and J.-F. Thisse (eds.), Handbook of Urban and Regional Economics, Vol. 4: 2119-2171. Amsterdam, Netherlands: Elsevier.

Sampat, B. N., D. C. Mowery, and A. A. Ziedonis. 2003. Changes in university patent quality after the Bayh-Dole Act: A re-examination. International Journal of Industrial Organization, 21: 1371-1390.

Saxenian, A. 1994. Regional Advantage: Culture and Competition in Silicon Valley and Route 128. Cambridge, Massachusetts: Harvard University Press.

Scherer, F. M. 1980. Industrial Market Structure and Economic Performance. 2nd Edition Ed. Boston: Houghton-Mifflin.

Scott, A. J. 1988. New Industrial Spaces: Flexible Production Organization and Regional Development in North America and Western Europe. London, United Kingdom: Pion Limited.

Tornatzky, L. G., and M. Fleischer. 1990. The Processes of Technological Innovation. Lexington, MA: Lexington Books.

United States Department of Agriculture. 2003. Measuring Rurality: Commuting Zones and Labor Market Areas. Available at http://www.ers.usda.gov/briefing/rurality/lmacz (accessed September 29, 2007).

Watts, H. D., A. M. Wood, and P. Wardle. 2003. 'Making friends or making things?': interfirm transactions in the Sheffield metal-working cluster. Urban Studies, 40 (3): 615-630. 
Table 1. Samples.

\begin{tabular}{|c|c|c|c|c|c|c|c|c|c|}
\hline \multirow{3}{*}{$\begin{array}{l}\text { SIC } \\
\text { Industry } \\
\text { Year }\end{array}$} & \multicolumn{3}{|c|}{30} & \multicolumn{3}{|c|}{354} & \multicolumn{3}{|c|}{382} \\
\hline & \multicolumn{3}{|c|}{ rubber \& plastics } & \multicolumn{3}{|c|}{ metalworking machinery } & \multicolumn{3}{|c|}{ measuring \& controlling devices } \\
\hline & 1992 & 1997 & 2002 & 1992 & 1997 & 2002 & 1992 & 1997 & 2002 \\
\hline Sample observations & 6,747 & 8,000 & 6,546 & 5,189 & 5,490 & 4,161 & 1,384 & 1,540 & 1,201 \\
\hline Dropped observations & 6,169 & 6,499 & 5,128 & 4,053 & 4,522 & 3,982 & 2,385 & 2,582 & 2,211 \\
\hline Percent retained in sample & 52.2 & 55.2 & 56.1 & 56.1 & 54.8 & 51.1 & 36.7 & 37.4 & 35.2 \\
\hline Mean employment & 78 & 82 & 91 & 33 & 38 & 36 & 97 & 94 & 111 \\
\hline Mean shipments & 9,912 & 12,789 & 16,259 & 3,417 & 5,191 & 5,185 & 12,891 & 17,603 & 22,393 \\
\hline Dominator establishments & 645 & 833 & 901 & 427 & 497 & 505 & 167 & 212 & 202 \\
\hline Percent & 9.6 & 10.4 & 13.8 & 8.2 & 9.1 & 12.1 & 12.1 & 13.8 & 16.8 \\
\hline Mean employment & 286 & 280 & 273 & 148 & 154 & 123 & 410 & 359 & 409 \\
\hline Mean shipments & 46,714 & 56,044 & 60,529 & 19,014 & 27,802 & 22,238 & 61,399 & 80,882 & 92,503 \\
\hline Dominated establishments & 3061 & 3701 & 2487 & 2686 & 2886 & 1846 & 658 & 687 & 505 \\
\hline Percent & 45.4 & 46.3 & 38.0 & 51.8 & 52.6 & 44.4 & 47.5 & 44.6 & 42.0 \\
\hline Mean employment & 23 & 24 & 26 & 13 & 15 & 15 & 21 & 23 & 23 \\
\hline Mean shipments & 1,835 & 2,254 & 2,835 & 964 & 1,462 & 1,562 & 1,958 & 2,800 & 3,056 \\
\hline Remainder of establishments & 3041 & 3466 & 3158 & 2076 & 2107 & 1810 & 559 & 641 & 494 \\
\hline Percent & 45.1 & 43.3 & 48.2 & 40.0 & 38.4 & 43.5 & 40.4 & 41.6 & 41.1 \\
\hline Mean employment & 89 & 97 & 91 & 36 & 41 & 34 & 93 & 82 & 80 \\
\hline Mean shipments & 10,236 & 13,642 & 14,199 & 3,384 & 4,966 & 4,122 & 11,269 & 12,540 & 13,491 \\
\hline
\end{tabular}

Note: Value of shipments reported in thousands of nominal dollars. 
Table 2. Variable Descriptives, Rubber and Plastics (SIC 30).

\begin{tabular}{|c|c|c|c|c|c|c|c|c|c|c|}
\hline \multirow{2}{*}{\multicolumn{2}{|c|}{ Year / Sample Size }} & \multicolumn{3}{|c|}{$1992(\mathrm{n}=6,747)$} & \multicolumn{3}{|c|}{$1997(\mathrm{n}=8,000)$} & \multicolumn{3}{|c|}{$2002(n=6,456)$} \\
\hline & & mean & std. dev. & $\%>m n$. & mean & std. dev. & $\%>\mathrm{mn}$. & mean & std. dev. & $\%>\mathrm{mn}$. \\
\hline Q & Output & 9,931 & 23,685 & 25.17 & 12,814 & 28,614 & 25.36 & 16,272 & 33,279 & 25.31 \\
\hline $\mathrm{K}$ & Capital & 4,856 & 16,606 & 21.73 & 6,286 & 19,748 & 22.16 & 9,166 & 24,751 & 22.53 \\
\hline $\mathrm{L}$ & Labor & 193 & 322 & 27.66 & 201 & 339 & 27.91 & 218 & 362 & 28.23 \\
\hline $\mathrm{E}$ & Energy & 18,997 & 54,866 & 22.62 & 22,199 & 64,385 & 21.93 & 28,054 & 81,757 & 21.77 \\
\hline M & Materials & 4,749 & 11,810 & 24.14 & 6,142 & 14,379 & 24.15 & 7,542 & 16,334 & 24.17 \\
\hline $\mathrm{S}_{\mathrm{K}}$ & Capital Cost Share & 13.82 & 8.01 & 39.91 & 17.81 & 9.28 & 48.56 & 21.13 & 10.23 & 46.62 \\
\hline $\mathrm{S}_{\mathrm{L}}$ & Labor Cost Share & 35.56 & 13.81 & 44.40 & 32.77 & 13.29 & 42.85 & 31.67 & 12.80 & 43.23 \\
\hline $\mathrm{S}_{\mathrm{E}}$ & Energy Cost Share & 2.89 & 2.32 & 38.34 & 2.39 & 1.92 & 34.91 & 2.35 & 1.93 & 36.80 \\
\hline $\mathrm{S}_{\mathrm{M}}$ & Materials Cost Share & 47.74 & 16.10 & 53.18 & 47.03 & 15.66 & 54.61 & 44.85 & 15.28 & 53.07 \\
\hline $\mathrm{C}$ & Concentration & 0.39 & 0.19 & 47.81 & 0.40 & 0.19 & 47.11 & 0.45 & 0.20 & 42.27 \\
\hline $\mathrm{AL}$ & Labor Pooling & 0.08 & 0.01 & 39.32 & 0.10 & 0.02 & 42.76 & 0.12 & 0.03 & 44.70 \\
\hline AI & Manufactured Inputs & 2,913 & 2,071 & 42.00 & 1,807 & 1,356 & 40.68 & 1,635 & 1,212 & 40.90 \\
\hline AS & Producer Services & 25,567 & 28,550 & 27.95 & 12,517 & 13,345 & 30.88 & 13,878 & 15,073 & 30.58 \\
\hline $\mathrm{AR}$ & Research & 330,729 & 242,436 & 38.94 & 406,037 & 274,997 & 41.69 & 501,543 & 322,954 & 41.87 \\
\hline $\mathrm{AP}$ & Patenting & 21.22 & 9.61 & 48.39 & 21.09 & 10.71 & 47.14 & 23.62 & 12.42 & 45.75 \\
\hline UE & Unemployment & 0.0714 & 0.0145 & 52.14 & 0.0443 & 0.0135 & 40.94 & 0.0566 & 0.0092 & 48.41 \\
\hline INC & Income & 36,028 & 4,655 & 44.60 & 41,339 & 5,606 & 46.95 & 45,419 & 6,902 & 47.63 \\
\hline POP & Population Density & 507.53 & 405.20 & 40.36 & 476.72 & 397.23 & 37.95 & 472.07 & 408.73 & 35.20 \\
\hline DV & Diversity & 0.0147 & 0.0037 & 37.02 & 0.0146 & 0.0043 & 37.51 & 0.0152 & 0.0055 & 32.29 \\
\hline $\mathrm{CH}$ & Historic Concentration & 0.58 & 0.21 & 44.79 & 0.55 & 0.22 & 48.79 & 0.49 & 0.24 & 46.52 \\
\hline DVH & Historic Diversity & 0.0139 & 0.0050 & 34.62 & 0.0149 & 0.0066 & 35.98 & 0.0161 & 0.0078 & 34.91 \\
\hline $\mathrm{D}$ & Dominator Firm (dummy) & & n.a. & & & n.a. & & & n.a. & \\
\hline $\mathrm{S}$ & Small Firm (dummy) & & n.a. & & & n.a. & & & n.a. & \\
\hline $\mathrm{R} 1-3$ & Census Region (dummies) & & n.a. & & & n.a. & & & n.a. & \\
\hline
\end{tabular}


Table 3. Variable Descriptives, Metalworking Machinery (SIC 354).

\begin{tabular}{|c|c|c|c|c|c|c|c|c|c|c|}
\hline \multicolumn{2}{|c|}{ Year / Sample Size } & \multicolumn{3}{|c|}{$1992(n=5,189)$} & \multicolumn{3}{|c|}{$1997(n=5,490)$} & \multicolumn{3}{|c|}{$2002(n=4,161)$} \\
\hline & & mean & std. dev. & $\%>\mathrm{mn}$ & mean & std. dev. & $\%>\mathrm{mn}$ & mean & std. dev. & $\%>\mathrm{mn}$ \\
\hline Q & Output & 3,424 & 11,539 & 19.31 & 5,242 & 19,903 & 19.00 & 5,178 & 18,096 & 20.04 \\
\hline K & Capital & 1,922 & 5,236 & 21.56 & 2,597 & 7,039 & 21.44 & 3,526 & 8,676 & 23.34 \\
\hline $\mathrm{L}$ & Labor & 81 & 185 & 23.38 & 92 & 227 & 23.72 & 83 & 171 & 25.19 \\
\hline E & Energy & 3,528 & 13,700 & 18.87 & 4,211 & 16,225 & 20.56 & 4,174 & 13,135 & 20.60 \\
\hline M & Materials & 1,220 & 5,561 & 15.94 & 2,086 & 12,031 & 15.50 & 2,015 & 10,540 & 16.32 \\
\hline $\mathrm{S}_{\mathrm{K}}$ & Capital Cost Share & 8.78 & 5.03 & 37.75 & 12.90 & 7.00 & 45.12 & 14.25 & 7.46 & 38.84 \\
\hline $\mathrm{S}_{\mathrm{L}}$ & Labor Cost Share & 57.86 & 13.13 & 50.34 & 54.40 & 13.06 & 57.12 & 53.18 & 13.67 & 53.86 \\
\hline $\mathrm{S}_{\mathrm{E}}$ & Energy Cost Share & 1.65 & 1.29 & 38.12 & 1.43 & 1.37 & 34.94 & 1.36 & 1.35 & 33.60 \\
\hline $\mathrm{S}_{\mathrm{M}}$ & Materials Cost Share & 31.72 & 13.92 & 48.43 & 31.27 & 14.52 & 40.09 & 31.21 & 14.96 & 42.13 \\
\hline $\mathrm{C}$ & Concentration & 0.41 & 0.20 & 46.98 & 0.44 & 0.21 & 48.43 & 0.45 & 0.20 & 42.20 \\
\hline $\mathrm{AL}$ & Labor Pooling & 0.12 & 0.01 & 47.95 & 0.15 & 0.01 & 55.01 & 0.12 & 0.02 & 56.28 \\
\hline AI & Manufactured Inputs & 3,297 & 1,883 & 48.20 & 3,025 & 1,650 & 47.74 & 2,797 & 1,609 & 45.61 \\
\hline AS & Producer Services & 22,113 & 22,927 & 31.18 & 9,866 & 9,857 & 30.46 & 10,660 & 11,130 & 30.09 \\
\hline AR & Research & 497,467 & 377,447 & 38.95 & 725,256 & 475,313 & 39.69 & 924,617 & 555,602 & 44.20 \\
\hline AP & Patenting & 18.37 & 6.78 & 48.24 & 18.52 & 8.31 & 46.28 & 21.02 & 10.07 & 48.88 \\
\hline UE & Unemployment & 0.0752 & 0.0167 & 50.16 & 0.0426 & 0.0087 & 59.02 & 0.0575 & 0.0079 & 49.34 \\
\hline INC & Income & 36,088 & 4,365 & 48.66 & 41,967 & 4,961 & 51.69 & 45,518 & 6,091 & 48.91 \\
\hline POP & Population Density & 506.71 & 351.12 & 46.68 & 499.22 & 355.29 & 44.77 & 491.59 & 361.58 & 41.82 \\
\hline DV & Diversity & 0.0153 & 0.0038 & 42.57 & 0.0145 & 0.0035 & 49.31 & 0.0147 & 0.0047 & 46.14 \\
\hline $\mathrm{CH}$ & Historic Concentration & 0.49 & 0.22 & 50.43 & 0.51 & 0.20 & 53.61 & 0.49 & 0.20 & 52.75 \\
\hline DVH & Historic Diversity & 0.0153 & 0.0071 & 38.77 & 0.0156 & 0.0075 & 39.03 & 0.0157 & 0.0058 & 38.84 \\
\hline $\mathrm{D}$ & Dominator Firm (dummy) & & n.a. & & & n.a. & & & n.a. & \\
\hline $\mathrm{S}$ & Small Firm (dummy) & & n.a. & & & n.a. & & & n.a. & \\
\hline $\mathrm{R} 1-3$ & Census Region (dummies) & & n.a. & & & n.a. & & & n.a. & \\
\hline
\end{tabular}


Table 4. Variable Descriptives, Measuring and Controlling Devices (SIC 382).

\begin{tabular}{|c|c|c|c|c|c|c|c|c|c|c|}
\hline \multirow{2}{*}{\multicolumn{2}{|c|}{ Year / Sample Size }} & \multicolumn{3}{|c|}{$1992(n=1,384)$} & \multicolumn{3}{|c|}{$1997(\mathrm{n}=1,540)$} & \multicolumn{3}{|c|}{$2002(\mathrm{n}=1,201)$} \\
\hline & & mean & std. dev. & $\%>m n$. & mean & std. dev. & $\%>\mathrm{mn}$. & mean & std. dev. & $\%>\mathrm{mn}$. \\
\hline Q & Output & 12,852 & 38,353 & 20.23 & 17,611 & 63,498 & 17.73 & 22,181 & 77,746 & 18.15 \\
\hline $\mathrm{K}$ & Capital & 4,744 & 15,682 & 18.50 & 5,854 & 25,133 & 17.47 & 8,880 & 33,063 & 16.82 \\
\hline $\mathrm{L}$ & Labor & 274 & 673 & 22.47 & 261 & 667 & 21.88 & 320 & 878 & 20.57 \\
\hline $\mathrm{E}$ & Energy & 7,787 & 24,120 & 17.05 & 8,065 & 29,751 & 17.27 & 9,039 & 33,750 & 16.74 \\
\hline M & Materials & 4,833 & 15,570 & 19.51 & 6,571 & 25,789 & 17.73 & 9,394 & 42,542 & 16.40 \\
\hline $\mathrm{S}_{\mathrm{K}}$ & Capital Cost Share & 10.27 & 6.43 & 33.38 & 13.46 & 7.43 & 47.08 & 14.12 & 7.92 & 44.88 \\
\hline $\mathrm{S}_{\mathrm{L}}$ & Labor Cost Share & 47.41 & 12.24 & 47.90 & 43.98 & 11.62 & 42.99 & 44.19 & 12.64 & 44.05 \\
\hline $\mathrm{S}_{\mathrm{E}}$ & Energy Cost Share & 1.16 & 1.06 & 40.53 & 1.02 & 1.28 & 32.60 & 0.83 & 0.80 & 30.97 \\
\hline $\mathrm{S}_{\mathrm{M}}$ & Materials Cost Share & 41.16 & 13.49 & 53.47 & 41.54 & 13.74 & 56.04 & 40.86 & 14.65 & 56.37 \\
\hline $\mathrm{C}$ & Concentration & 0.54 & 0.18 & 44.51 & 0.59 & 0.15 & 45.52 & 0.64 & 0.14 & 38.38 \\
\hline $\mathrm{AL}$ & Labor Pooling & 0.14 & 0.02 & 39.45 & 0.20 & 0.03 & 42.53 & 0.15 & 0.03 & 40.88 \\
\hline AI & Manufactured Inputs & 1,728 & 2,167 & 25.22 & 2,374 & 4,113 & 18.31 & 2,051 & 3,194 & 22.90 \\
\hline AS & Producer Services & 7,089 & 4,425 & 50.51 & 4,401 & 3,039 & 47.79 & 5,268 & 3,809 & 46.54 \\
\hline $\mathrm{AR}$ & Research & 160,186 & 229,831 & 22.90 & 185,002 & 267,781 & 29.48 & 201,325 & 261,265 & 27.81 \\
\hline $\mathrm{AP}$ & Patenting & 61.57 & 24.77 & 40.25 & 72.12 & 39.13 & 32.21 & 96.29 & 70.24 & 35.97 \\
\hline UE & Unemployment & 0.0731 & 0.0133 & 57.30 & 0.0431 & 0.0084 & 47.14 & 0.0575 & 0.0105 & 40.97 \\
\hline INC & Income & 39,442 & 4,448 & 53.18 & 45,485 & 5,234 & 54.29 & 51,215 & 6,751 & 48.38 \\
\hline POP & Population Density & 681.93 & 390.05 & 45.66 & 677.29 & 390.98 & 42.34 & 698.59 & 396.70 & 42.63 \\
\hline DV & Diversity & 0.0134 & 0.0019 & 39.60 & 0.0130 & 0.0021 & 26.75 & 0.0131 & 0.0024 & 44.96 \\
\hline $\mathrm{CH}$ & Historic Concentration & 0.74 & 0.16 & 51.73 & 0.70 & 0.17 & 41.30 & 0.65 & 0.18 & 42.38 \\
\hline DVH & Historic Diversity & 0.0126 & 0.0031 & 36.13 & 0.0127 & 0.0035 & 35.71 & 0.0134 & 0.0032 & 40.30 \\
\hline $\mathrm{D}$ & Dominator Firm (dummy) & & n.a. & & & n.a. & & & n.a. & \\
\hline S & Small Firm (dummy) & & n.a. & & & n.a. & & & n.a. & \\
\hline R1-3 & Census Region (dummies) & & n.a. & & & n.a. & & & n.a. & \\
\hline
\end{tabular}


Table 5. Pearson Pairwise Correlation Coefficients Among Selected Independent Variables.

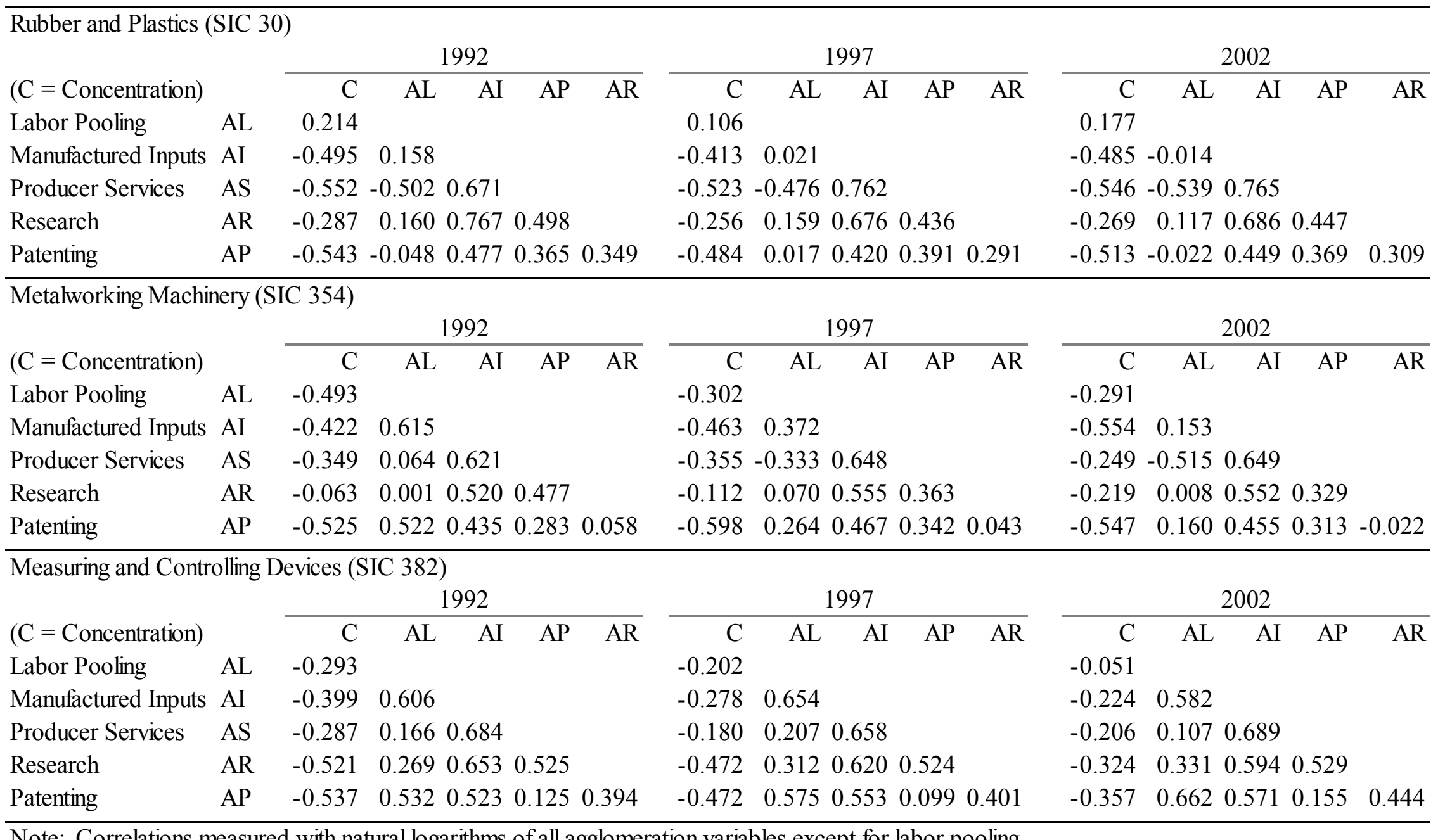

Note: Correlations measured with natural logarithms of all agglomeration variables except for labor pooling. 
Table 6. Parameter Estimates, Rubber and Plastics (SIC 30).

\begin{tabular}{|c|c|c|c|c|c|c|c|c|c|c|c|c|c|c|c|c|c|c|c|}
\hline \multirow{3}{*}{$\begin{array}{l}\text { Year } \\
\text { Variable } \\
\text { constant }\end{array}$} & \multicolumn{3}{|c|}{1992} & \multicolumn{3}{|c|}{1997} & \multicolumn{3}{|c|}{2002} & \multirow{3}{*}{$\begin{array}{l}\text { Year } \\
\text { Variable } \\
\ln \mathrm{AI} \cdot \ln \mathrm{K}\end{array}$} & \multicolumn{3}{|c|}{1992} & \multicolumn{3}{|c|}{1997} & \multicolumn{3}{|c|}{2002} \\
\hline & Coeff. & td. Err. & p-Val. & Coeff. $S$ & td. Err. & o-Val. & Coeff. & td. Err. & p-Val. & & Coeff. St & td. Err. & p-Val. & Coeff. S & d. Err. & p-Val. & Coeff. S & d. Err. & p-Val. \\
\hline & 8.278 & 0.013 & 0.00 & 8.436 & 0.012 & 0.00 & 8.788 & 0.015 & 0.00 & & 0.004 & 008 & 0.62 & 0.003 & 0.007 & 0.61 & 0.001 & 0.010 & 0.91 \\
\hline$n \mathrm{~K}$ & 0.130 & 0.002 & 0.00 & 0.168 & 0.002 & 0.00 & 0.198 & 0.003 & 0.00 & $\mathrm{AI} \cdot \ln \mathrm{L}$ & 0.000 & 0.007 & 0.98 & 0.000 & 0.005 & 0.94 & -0.002 & 0.007 & 0.81 \\
\hline $\mathrm{L}$ & 0.334 & 0.003 & 0.00 & 0.308 & 0.002 & 0.00 & 0.298 & 0.003 & 0.00 & $\mathrm{AI} \cdot \ln \mathrm{E}$ & 0.001 & 0.012 & 0.93 & 0.000 & 0.009 & 0.99 & 0.000 & 0.012 & 0.97 \\
\hline $\mathrm{E}$ & 0.027 & 0.003 & 0.00 & 0.023 & 0.003 & 0.00 & 022 & 0.004 & 0.00 & $\mathrm{AI} \cdot \ln \mathrm{M}$ & 0.014 & 0.008 & 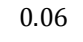 & 0.000 & 006 & 0.96 & .003 & 0.010 & 0.73 \\
\hline $\mathrm{M}$ & 0.447 & 0.003 & 0.00 & 0.443 & 0.003 & 0.00 & 0.418 & 0.004 & 0.00 & $\mathrm{AS} \cdot \ln \mathrm{K}$ & -0.002 & 0.006 & 0.70 & -0.004 & 0.007 & 0.61 & 0.001 & 0.009 & 0.93 \\
\hline$(\ln K)^{2}$ & 0.085 & 0.004 & 0.00 & 0.096 & 0.005 & 0.00 & 0.102 & 0.013 & 0.00 & $\mathrm{AS} \cdot \ln \mathrm{L}$ & 0.007 & 0.005 & 0.22 & 0.001 & 0.005 & 0.83 & 0.005 & 0.007 & 0.45 \\
\hline$(\ln L)^{2}$ & 0.142 & 0.003 & 0.00 & 0.138 & 0.003 & 0.00 & 0.119 & 0.005 & 0.00 & $\mathrm{AS} \cdot \ln \mathrm{E}$ & 0.001 & 0.010 & 0.92 & 0.000 & 0.009 & 0.98 & 0.000 & 0.012 & 0.97 \\
\hline$n E)^{2}$ & 0.019 & 0.005 & 0.00 & 0.017 & 0.005 & 0.00 & 0.016 & 0.006 & 0.01 & $\mathrm{AS} \cdot \ln \mathrm{M}$ & -0.007 & 0.007 & 0.33 & -0.003 & 0.006 & 0.59 & 0.003 & 0.010 & 0.76 \\
\hline$(\ln M)^{2}$ & 0.172 & 0.004 & 0.00 & 0.179 & 0.004 & 0.00 & 0.157 & 0.010 & 0.00 & $\mathrm{AR} \cdot \ln \mathrm{K}$ & -0.001 & 0.005 & 0.90 & 0.002 & 0.003 & 0.63 & 0.002 & 0.005 & 0.64 \\
\hline $\mathrm{K} \cdot \ln \mathrm{L}$ & -0.032 & 0.002 & 0. & -0.033 & 0.003 & 0.0 & -0.038 & 0.007 & & $\cdot \ln \mathrm{L}$ & 0.003 & 004 & & & 003 & & 03 & 04 & 0.39 \\
\hline$K \cdot \ln E$ & -0.003 & 0.003 & 0.43 & -0.002 & 0.003 & 0.52 & -0.003 & 0.006 & 0.5 & $A R \cdot \ln E$ & 0.001 & 0.008 & 0.89 & 0.002 & 0.005 & 0.75 & 0.002 & 0.007 & 0.81 \\
\hline $\mathrm{K} \cdot \ln \mathrm{M}$ & -0.056 & 0.003 & 0 . & -0.067 & 0.003 & 0.0 & -0.073 & 0.006 & & $\cdot \ln M$ & -0.007 & 05 & & 02 & 003 & & -0.001 & 05 & 0.79 \\
\hline$L \cdot \ln E$ & -0.005 & 0.003 & 0.12 & -0.005 & 0.003 & 0.08 & -0.003 & 0.005 & 0.55 & $\mathrm{AP} \cdot \ln \mathrm{K}$ & 0.002 & 0.005 & 0.77 & -0.003 & 0.007 & 0.67 & 0.000 & 0.006 & 1.00 \\
\hline $\mathrm{L} \cdot \ln \mathrm{M}$ & -0.114 & 0.003 & & -0.108 & 0.002 & $0 .($ & -0.094 & 6 & & $\cdot \ln L$ & 0.007 & 05 & & 88 & 004 & & 011 & 05 & 0.03 \\
\hline$E \cdot \ln M$ & -0.012 & 0.003 & 0 & -0.010 & 0.003 & 0.0 & -0.011 & 0.005 & 0.0 & $\ln E$ & 0.000 & 0.008 & 0. & 0.000 & 0.008 & 0.97 & 0.001 & 0.008 & 0.93 \\
\hline $\mathrm{C}$ & -0.045 & 0.040 & 0 & -0.051 & 0.036 & 0.1 & -0.065 & 38 & 0. & $M$ & -0.007 & 06 & 0.25 & 09 & 005 & 6 & 4 & 6 & 0.49 \\
\hline $\mathrm{L}$ & 0.900 & 0.609 & 0 & 0.040 & 0.348 & 0.9 & 0.686 & 0.375 & 0.0 & D & 0.141 & 0.015 & 0. & 0.149 & 0.014 & 0.00 & 0.192 & 0.017 & 0.00 \\
\hline $\mathrm{AI}$ & 0.005 & 0.014 & $0.6 \mathrm{c}$ & 0.000 & 0.012 & 0.9 & -0.011 & 0.013 & 0.4 & & -0.191 & 0.011 & 0.00 & -0.174 & 0.012 & 0.00 & -0.159 & 0.013 & 0.00 \\
\hline AS & -0.005 & 0.013 & 0.68 & 0.000 & 0.013 & 0.97 & 0.016 & 0.014 & 0.2 & & -0.019 & 0.016 & 0.23 & 0.018 & 0.013 & 0.18 & 0.001 & 0.016 & 0.95 \\
\hline $\mathrm{AR}$ & 0.002 & 0.009 & 0.8 & 0.007 & 0.007 & 0.32 & 0.005 & 0.009 & 0.52 & & -0.004 & 0.014 & 0.75 & 0.003 & 0.015 & 0.84 & -0.013 & 0.017 & 0.43 \\
\hline $\mathrm{AP}$ & 0.003 & 0.013 & 0.82 & 0.020 & 0.010 & 0.05 & 0.021 & 0.011 & 0.07 & R3 & -0.023 & 0.019 & 0.23 & -0.002 & 0.016 & 0.91 & -0.018 & 0.021 & 0.39 \\
\hline$C^{2}$ & -0.451 & 0.265 & 0.09 & -0.301 & 0.251 & 0.23 & -1.057 & 0.299 & 0.0 & & 0.024 & 0.009 & 0.01 & 0.006 & 0.008 & 0.45 & 0.001 & 0.009 & 0.93 \\
\hline$\cdot \mathrm{AL}$ & 0.372 & 2.975 & 0.90 & -1.368 & 1.149 & 0.23 & -0.850 & 1.532 & 0.58 & UE & -0.485 & 0.320 & 0.13 & 0.683 & 0.325 & 0.04 & -0.251 & 0.533 & 0.64 \\
\hline$\cdot \ln \mathrm{AI}$ & 0.024 & 0.065 & 0.7 & 0.035 & 0.052 & 0.50 & 0.014 & 0.062 & 0.8 & & 0.139 & 0.056 & 0.01 & 0.095 & 0.046 & 0.04 & 0.090 & 0.051 & 0.08 \\
\hline$\cdot \ln \mathrm{AS}$ & -0.046 & 0.050 & 0.36 & -0.044 & 0.048 & 0.36 & -0.106 & 0.062 & 0.09 & DV & 1.609 & 1.263 & 0.20 & -1.494 & 1.027 & 0.15 & 0.554 & 0.907 & 0.54 \\
\hline $\mathrm{AR}$ & 0.039 & 0.039 & & 0.041 & 0.030 & 0.1 & 0.033 & 0.042 & 0.4 & & -0.012 & 0.029 & 0.69 & -0.002 & 0.028 & 0.94 & -0.060 & 0.038 & 0.11 \\
\hline$\cdot \ln \mathrm{AP}$ & -0.061 & 0.048 & 0.21 & -0.014 & 0.046 & 0.76 & -0.123 & 0.049 & 0.01 & $\mathrm{VH}$ & -0.148 & 0.997 & 0.88 & -0.349 & 0.642 & 0.59 & 0.735 & 0.745 & 0.32 \\
\hline$\cdot \ln \mathrm{K}$ & 0.021 & 0.015 & 0.17 & 0.006 & 0.018 & 0.73 & 0.012 & 0.026 & 0. & & & & & & & & & & \\
\hline$C \cdot \ln \mathrm{L}$ & 0.027 & 0.016 & 0.09 & -0.003 & 0.012 & 0.81 & 0.023 & 0.017 & 0.19 & & & & & & & & & & \\
\hline$\cdot \ln E$ & 0.001 & 0.025 & 0.96 & -0.002 & 0.024 & 0.92 & 0.001 & 0.030 & 0.98 & 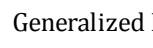 & & & 0.999 & & & 0.999 & & & 0.999 \\
\hline $\mathrm{C} \cdot \ln \mathrm{M}$ & 0.035 & 0.021 & 0.10 & -0.006 & 0.016 & 0.70 & 0.017 & 0.026 & 0.53 & Equation Adj & justed $\mathrm{R}^{2}$ & & & & & & & & \\
\hline $\mathrm{AL} \cdot \ln \mathrm{K}$ & -0.082 & 0.322 & 0.80 & 0.025 & 0.173 & 0.88 & 0.159 & 0.240 & 0.51 & Productior & n Functior & & 0.957 & & & 0.963 & & & 0.949 \\
\hline & 0.056 & 0.296 & & -0.105 & 0.118 & 0.3 & 0.078 & 0.162 & 0.6 & Capital Cos & st Share & & 0.779 & & & 0.797 & & & 0.781 \\
\hline $\mathrm{AL} \cdot \ln \mathrm{E}$ & -0.093 & 0.519 & 0.86 & -0.070 & 0.217 & 0.75 & -0.067 & 0.279 & 0.81 & Labor Cost & t Share & & 0.751 & & & 0.765 & & & 0.696 \\
\hline $\mathrm{L} \cdot \ln \mathrm{M}$ & 0.083 & 0.383 & 0.83 & 0.119 & 0.139 & 0.39 & 0.380 & 0.194 & 0.05 & Materials & Cost Share & & 0.875 & & & 0.884 & & & 0.858 \\
\hline
\end{tabular}

Notes: Standard errors are corrected for heteroskedasticity. See Table 2, 3, or 4 for abbreviation explanations. 
Table 7. Parameter Estimates, Metalworking Machinery (SIC 354).

\begin{tabular}{|c|c|c|c|c|c|c|c|c|c|c|c|c|c|c|c|c|c|c|c|}
\hline \multirow{3}{*}{$\begin{array}{l}\text { Year } \\
\text { Variable } \\
\text { constant }\end{array}$} & \multicolumn{3}{|c|}{1992} & \multicolumn{3}{|c|}{1997} & \multicolumn{3}{|c|}{2002} & \multirow{3}{*}{$\begin{array}{l}\text { Year } \\
\text { Variable } \\
\ln \mathrm{AI} \cdot \ln \mathrm{K}\end{array}$} & \multicolumn{3}{|c|}{1992} & \multicolumn{3}{|c|}{1997} & \multicolumn{3}{|c|}{2002} \\
\hline & Coeff. & td. Err. & p-Val. & Coeff. & td. Err. & p-Val. & Coeff. $\subseteq$ & td. Err. & p-Val. & & Coeff. St & td. Err. & p-Val. & Coeff. & td. Err. & p-Val. & Coeff. & td. Err. & p-Val. \\
\hline & 7.152 & 0.016 & 0.00 & 7.382 & 0.017 & 0.00 & 7.560 & 0.017 & 0.00 & & 0.003 & 0.006 & 0.63 & 0.001 & 0.011 & 0.96 & -0.001 & 0.009 & 0.93 \\
\hline $\ln K$ & 0.085 & 0.002 & 0.00 & 0.124 & 0.002 & 0.00 & 0.135 & 0.003 & 0.00 & $\ln \mathrm{AI} \cdot \ln \mathrm{L}$ & 0.008 & 0.009 & 0.38 & 0.004 & 0.010 & 0.67 & -0.015 & 0.011 & 0.18 \\
\hline $\ln \mathrm{L}$ & 0.562 & 0.005 & 0.00 & 0.520 & 0.004 & 0.00 & 0.505 & 0.005 & 0.00 & $\ln \mathrm{AI} \cdot \ln \mathrm{E}$ & -0.001 & 0.011 & 0.93 & 0.000 & 0.016 & 0.98 & 0.000 & 0.013 & 0.98 \\
\hline $\ln E$ & 0.016 & 0.004 & 0.00 & 0.014 & 0.004 & 0.00 & 0.013 & 0.004 & 0.00 & $\ln \mathrm{AI} \cdot \ln \mathrm{M}$ & 0.010 & 0.007 & 0.18 & -0.001 & 0.009 & 0.91 & -0.004 & 0.009 & 0.62 \\
\hline $\ln M$ & 0.308 & 0.003 & 0.00 & 0.300 & 0.003 & 0.00 & 0.294 & 0.004 & 0.00 & $\ln \mathrm{AS} \cdot \ln \mathrm{K}$ & -0.002 & 0.004 & 0.63 & -0.002 & 0.008 & 0.78 & 0.003 & 0.007 & 0.67 \\
\hline$(\ln K)^{2}$ & 0.064 & 0.004 & 0.00 & 0.080 & 0.007 & 0.00 & 0.080 & 0.005 & 0.00 & $\ln \mathrm{AS} \cdot \ln \mathrm{L}$ & -0.006 & 0.006 & 0.35 & 0.002 & 0.008 & 0.78 & 0.023 & 0.009 & 0.01 \\
\hline$(\ln L)^{2}$ & 0.183 & 0.006 & 0.00 & 0.175 & 0.007 & 0.00 & 0.141 & 0.006 & 0.00 & $\ln \mathrm{AS} \cdot \ln \mathrm{E}$ & 0.001 & 0.007 & 0.87 & 0.000 & 0.012 & 0.99 & 0.000 & 0.010 & 0.97 \\
\hline$(\ln E)^{2}$ & 0.013 & 0.008 & 0.10 & 0.013 & 0.008 & 0.12 & 0.011 & 0.005 & 0.03 & $\ln \mathrm{AS} \cdot \ln \mathrm{M}$ & -0.006 & 0.005 & 0.20 & -0.001 & 0.006 & 0.94 & 0.010 & 0.008 & 0.17 \\
\hline$(\ln M)^{2}$ & 0.170 & 0.005 & 0.00 & 0.174 & 0.009 & 0.00 & 0.154 & 0.005 & 0.00 & $\ln \mathrm{AR} \cdot \ln \mathrm{K}$ & 0.000 & 0.004 & 0.93 & 0.001 & 0.005 & 0.91 & -0.002 & 0.005 & 0.66 \\
\hline $\ln \mathrm{K} \cdot \ln \mathrm{L}$ & -0.038 & 0.004 & 0.00 & -0.046 & 0.005 & 0.00 & -0.047 & 0.004 & 0.00 & $\ln \mathrm{AR} \cdot \ln \mathrm{L}$ & 0.005 & 0.005 & 0.36 & -0.010 & 0.005 & 0.03 & -0.010 & 0.006 & 0.10 \\
\hline $\ln \mathrm{K} \cdot \ln \mathrm{E}$ & -0.001 & 0.004 & 0.82 & -0.001 & 0.004 & 0.75 & -0.001 & 0.003 & 0.72 & $\ln \mathrm{AR} \cdot \ln \mathrm{E}$ & 0.001 & 0.006 & 0.82 & 0.001 & 0.007 & 0.84 & 0.001 & 0.008 & 0.89 \\
\hline $\ln \mathrm{K} \cdot \ln \mathrm{M}$ & -0.029 & 0.002 & 0.00 & -0.038 & 0.003 & 0.00 & -0.040 & 0.003 & 0.00 & $\ln \mathrm{AR} \cdot \ln \mathrm{M}$ & 0.002 & 0.004 & 0.68 & 0.002 & 0.004 & 0.66 & -0.004 & 0.005 & 0.40 \\
\hline $\ln \mathrm{L} \cdot \ln \mathrm{E}$ & -0.006 & 0.005 & 0.20 & -0.006 & 0.006 & 0.34 & -0.005 & 0.004 & 0.24 & $\ln \mathrm{AP} \cdot \ln \mathrm{K}$ & -0.001 & 0.006 & 0.86 & 0.003 & 0.006 & 0.66 & 0.001 & 0.007 & 0.89 \\
\hline $\ln \mathrm{L} \cdot \ln \mathrm{M}$ & -0.140 & 0.004 & 0.00 & -0.131 & 0.006 & 0.00 & -0.119 & 0.004 & 0.00 & $\ln \mathrm{AP} \cdot \ln \mathrm{L}$ & 0.002 & 0.010 & 0.86 & 0.004 & 0.007 & 0.64 & 0.012 & 0.009 & 0.18 \\
\hline $\ln \mathrm{E} \cdot \ln \mathrm{M}$ & -0.006 & 0.005 & 0.19 & -0.006 & 0.007 & 0.39 & -0.006 & 0.003 & 0.10 & $\ln \mathrm{AP} \cdot \ln \mathrm{E}$ & 0.001 & 0.012 & 0.95 & 0.001 & 0.010 & 0.89 & 0.001 & 0.010 & 0.96 \\
\hline C & -0.088 & 0.042 & 0.04 & -0.200 & 0.041 & 0.00 & -0.190 & 0.053 & 0.00 & $\ln \mathrm{AP} \cdot \ln \mathrm{M}$ & -0.004 & 0.007 & 0.60 & 0.005 & 0.006 & 0.45 & 0.000 & 0.007 & 0.98 \\
\hline $\mathrm{AL}$ & -0.512 & 1.000 & 0.61 & -2.826 & 0.946 & 0.00 & 0.060 & 0.627 & 0.92 & D & 0.178 & 0.020 & 0.00 & 0.210 & 0.019 & 0.00 & 0.217 & 0.024 & 0.00 \\
\hline $\ln \mathrm{AI}$ & 0.024 & 0.018 & 0.18 & 0.030 & 0.019 & 0.11 & -0.040 & 0.019 & 0.03 & $\mathrm{~S}$ & -0.173 & 0.014 & 0.00 & -0.125 & 0.013 & 0.00 & -0.158 & 0.017 & 0.00 \\
\hline $\ln$ AS & -0.012 & 0.013 & 0.38 & -0.046 & 0.016 & 0.01 & 0.025 & 0.017 & 0.14 & $\mathrm{R} 1$ & -0.025 & 0.025 & 0.32 & 0.077 & 0.024 & 0.00 & -0.014 & 0.028 & 0.62 \\
\hline In AR & -0.029 & 0.011 & 0.01 & 0.005 & 0.011 & 0.67 & -0.019 & 0.011 & 0.08 & $\mathrm{R} 2$ & 0.014 & 0.017 & 0.40 & 0.067 & 0.020 & 0.00 & 0.034 & 0.019 & 0.08 \\
\hline $\ln \mathrm{AP}$ & 0.076 & 0.019 & 0.00 & 0.083 & 0.015 & 0.00 & 0.106 & 0.019 & 0.00 & R3 & -0.085 & 0.026 & 0.00 & 0.007 & 0.024 & 0.78 & -0.097 & 0.031 & 0.00 \\
\hline$c^{2}$ & 0.287 & 0.306 & 0.35 & 0.821 & 0.277 & 0.00 & -0.052 & 0.366 & 0.89 & $\ln \mathrm{POP}$ & 0.036 & 0.010 & 0.00 & 0.016 & 0.009 & 0.09 & 0.021 & 0.013 & 0.11 \\
\hline $\mathrm{C} \cdot \mathrm{AL}$ & -1.368 & 5.117 & 0.79 & -2.749 & 3.456 & 0.43 & 0.801 & 2.591 & 0.76 & UE & 0.589 & 0.366 & 0.11 & -0.113 & 0.695 & 0.87 & 2.159 & 0.829 & 0.01 \\
\hline$C \cdot \ln A \mathrm{I}$ & -0.095 & 0.087 & 0.27 & 0.023 & 0.090 & 0.80 & -0.099 & 0.088 & 0.26 & $\ln$ INC & -0.024 & 0.079 & 0.76 & -0.105 & 0.076 & 0.17 & -0.187 & 0.097 & 0.05 \\
\hline$C \cdot \ln A S$ & 0.051 & 0.054 & 0.34 & 0.041 & 0.063 & 0.51 & 0.132 & 0.073 & 0.07 & DV & -3.146 & 1.281 & 0.01 & -4.041 & 1.446 & 0.01 & -4.031 & 1.406 & 0.00 \\
\hline$C \cdot \ln A R$ & 0.013 & 0.041 & 0.76 & -0.040 & 0.040 & 0.32 & -0.018 & 0.047 & 0.71 & $\mathrm{CH}$ & -0.018 & 0.041 & 0.66 & -0.014 & 0.037 & 0.70 & 0.222 & 0.051 & 0.00 \\
\hline $\mathrm{C} \cdot \ln \mathrm{AP}$ & 0.035 & 0.087 & 0.69 & 0.029 & 0.059 & 0.62 & -0.121 & 0.073 & 0.10 & DVH & 0.557 & 1.098 & 0.61 & -0.920 & 0.813 & 0.26 & -0.497 & 1.174 & 0.67 \\
\hline$C \cdot \ln \mathrm{K}$ & 0.004 & 0.015 & 0.78 & 0.008 & 0.015 & 0.59 & 0.019 & 0.019 & 0.31 & & & & & & & & & & \\
\hline$C \cdot \ln L$ & -0.025 & 0.019 & 0.19 & -0.030 & 0.018 & 0.09 & 0.000 & 0.025 & 0.99 & & & & & & & & & & \\
\hline$C \cdot \ln E$ & -0.001 & 0.025 & 0.95 & 0.001 & 0.028 & 0.97 & 0.001 & 0.030 & 0.98 & Generalized & & & 0.999 & & & 0.999 & & & 0.999 \\
\hline$C \cdot \ln M$ & 0.023 & 0.015 & 0.13 & 0.028 & 0.019 & 0.13 & 0.031 & 0.021 & 0.14 & Equation Adj & justed $\mathrm{R}^{2}$ & & & & & & & & \\
\hline $\mathrm{AL} \cdot \ln \mathrm{K}$ & -0.050 & 0.385 & 0.90 & -0.072 & 0.378 & 0.85 & 0.048 & 0.233 & 0.84 & Productior & n Functiol & & 0.942 & & & 0.952 & & & 0.935 \\
\hline$A L \cdot \ln L$ & 0.407 & 0.516 & 0.43 & 0.167 & 0.387 & 0.67 & 0.594 & 0.325 & 0.07 & Capital Cos & st Share & & 0.761 & & & 0.758 & & & 0.754 \\
\hline$A L \cdot \ln E$ & 0.055 & 0.659 & 0.93 & -0.066 & 0.584 & 0.91 & -0.063 & 0.388 & 0.87 & Labor Cost & t Share & & 0.745 & & & 0.739 & & & 0.737 \\
\hline$A L \cdot \ln M$ & -0.020 & 0.438 & 0.96 & 0.040 & 0.303 & 0.90 & 0.128 & 0.274 & 0.64 & Materials & Cost Share & & 0.851 & & & 0.878 & & & 0.858 \\
\hline
\end{tabular}

Notes: Standard errors are corrected for heteroskedasticity. See Table 2, 3, or 4 for abbreviation explanations. 
Table 8. Parameter Estimates, Measuring and Controlling Devices (SIC 382).

\begin{tabular}{|c|c|c|c|c|c|c|c|c|c|c|c|c|c|c|c|c|c|c|c|}
\hline \multirow{3}{*}{$\begin{array}{l}\text { Year } \\
\text { Variable } \\
\text { constant }\end{array}$} & \multicolumn{3}{|c|}{1992} & \multicolumn{3}{|c|}{1997} & \multicolumn{3}{|c|}{2002} & \multirow{2}{*}{$\begin{array}{l}\text { Year } \\
\text { Variable }\end{array}$} & \multicolumn{3}{|c|}{1992} & \multicolumn{3}{|c|}{1997} & \multicolumn{3}{|c|}{2002} \\
\hline & Coef & td. Er & p-Val. & C & td. Er & p-Val. & C & td. Err. & p-Val. & & C & td. Err. & $\mathrm{p}-$ & Coeff. & td. Err. & $\mathrm{p}-$ & Coeff. & d. Err. & p-Val. \\
\hline & 8.279 & 0.042 & 0.00 & 8.491 & 0.029 & 0.00 & 8.773 & 0.048 & 0.00 & $\ln \mathrm{AI} \cdot \ln \mathrm{K}$ & 0.010 & 0.012 & 0.43 & 0.003 & 0.007 & 0.68 & 0.003 & 0.008 & 0.71 \\
\hline $\ln \mathrm{K}$ & 0.094 & 0.006 & 0.00 & 0.122 & 0.005 & 0.00 & 0.128 & 0.006 & 0.00 & $\ln \mathrm{AI} \cdot \ln \mathrm{L}$ & 0.028 & 0.014 & 0.04 & 0.004 & 0.008 & 0.56 & 0.004 & 0.009 & 0.66 \\
\hline In L & 0.431 & 0.008 & 0.00 & 0.398 & 0.008 & 0.00 & 0.396 & 0.009 & 0.00 & $\ln \mathrm{AI} \cdot \ln \mathrm{E}$ & 0.001 & 0.021 & 0.95 & 0.000 & 0.012 & 0.99 & 0.001 & 0.015 & 0.94 \\
\hline $\ln E$ & 0.011 & 0.013 & 0.41 & 0.009 & 0.008 & 0.27 & 0.008 & 0.011 & 0.48 & $\ln \mathrm{AI} \cdot \ln \mathrm{M}$ & 0.030 & 0.013 & 0.03 & 0.006 & 0.010 & 0.58 & 0.010 & 0.010 & 0.30 \\
\hline$n \mathrm{M}$ & 0.374 & 0.014 & 0.00 & 0.377 & 0.008 & 0.00 & 0.367 & 0.009 & 0.00 & $\ln \mathrm{AS} \cdot \ln \mathrm{K}$ & -0.005 & 0.010 & 0.59 & -0.003 & 0.007 & 0.68 & -0.004 & 0.012 & 0.73 \\
\hline$(\ln K)^{2}$ & 0.072 & 0.035 & 0.04 & 0.073 & 0.008 & 0.00 & 0.065 & 0.021 & 0.00 & $\ln \mathrm{AS} \cdot \ln \mathrm{L}$ & -0.016 & 0.009 & 0.07 & -0.001 & 0.007 & 0.93 & -0.001 & 0.012 & 0.91 \\
\hline$(\ln L)^{2}$ & 0.135 & 0.021 & 0.00 & 0.121 & 0.008 & 0.00 & 0.121 & 0.013 & 0.00 & $\ln \mathrm{AS} \cdot \ln \mathrm{E}$ & -0.001 & 0.014 & 0.96 & 0.000 & 0.010 & 0.99 & -0.001 & 0.018 & 0.96 \\
\hline$(\ln E)^{2}$ & 0.008 & 0.044 & 0.85 & 0.009 & 0.011 & 0.40 & 0.006 & 0.024 & 0.79 & $\ln \mathrm{AS} \cdot \ln \mathrm{M}$ & -0.019 & 0.008 & 0.02 & -0.005 & 0.010 & 0.64 & -0.014 & 0.010 & 0.17 \\
\hline$(\ln M)^{2}$ & 0.146 & 0.021 & 0.00 & 0.158 & 0.012 & 0.00 & 0.145 & 0.013 & 0.00 & $\ln \mathrm{AR} \cdot \ln \mathrm{K}$ & -0.001 & 0.005 & 0.90 & -0.001 & 0.004 & 0.70 & 0.001 & 0.011 & 0.93 \\
\hline $\ln \mathrm{K} \cdot \ln \mathrm{L}$ & -0.036 & 0.031 & 0.24 & -0.026 & 0.004 & 0.00 & -0.026 & 0.015 & 0.08 & $\ln \mathrm{AR} \cdot \ln \mathrm{L}$ & 0.013 & 0.006 & 0.03 & 0.009 & 0.004 & 0.04 & 0.005 & 0.008 & 0.54 \\
\hline $\ln \mathrm{K} \cdot \ln \mathrm{E}$ & 0.000 & 0.041 & 1.00 & -0.002 & 0.008 & 0.80 & -0.001 & 0.013 & 0.95 & $\ln \mathrm{AR} \cdot \ln \mathrm{E}$ & 0.000 & 0.008 & 0.98 & 0.000 & 0.006 & 0.97 & 0.000 & 0.016 & 0.98 \\
\hline $\ln K \cdot \ln M$ & -0.040 & 0.028 & 0.16 & -0.048 & 0.008 & 0.00 & -0.043 & 0.017 & 0.01 & $\ln \mathrm{AR} \cdot \ln \mathrm{M}$ & 0.003 & 0.006 & 0.60 & -0.002 & 0.004 & 0.59 & 0.001 & 0.007 & 0.89 \\
\hline$n L \cdot \ln E$ & -0.003 & 0.028 & 0.91 & -0.002 & 0.007 & 0.82 & -0.002 & 0.010 & 0.85 & $\ln \mathrm{AP} \cdot \ln \mathrm{K}$ & 0.000 & 0.035 & 1.00 & -0.001 & 0.015 & 0.95 & 0.004 & 0.035 & 0.90 \\
\hline $\ln \mathrm{L} \cdot \ln \mathrm{M}$ & -0.108 & 0.025 & 0.00 & -0.107 & 0.006 & 0.00 & -0.105 & 0.014 & 0.00 & $\ln \mathrm{AP} \cdot \ln \mathrm{L}$ & 0.027 & 0.024 & 0.27 & 0.017 & 0.014 & 0.22 & 0.028 & 0.027 & 0.30 \\
\hline$n E \cdot \ln M$ & -0.005 & 0.031 & 0.87 & -0.005 & 0.006 & 0.35 & -0.004 & 0.009 & 0.66 & $\ln \mathrm{AP} \cdot \ln \mathrm{E}$ & -0.001 & 0.044 & 0.98 & 0.001 & 0.022 & 0.95 & 0.000 & 0.060 & 0.99 \\
\hline 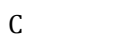 & -0.353 & 0.176 & 0.05 & -0.250 & 0.144 & 0.08 & 0.118 & 0.173 & 0.49 & $\ln \mathrm{AP} \cdot \ln \mathrm{M}$ & -0.003 & 0.023 & 0.89 & 0.002 & 0.017 & 0.90 & -0.002 & 0.025 & 0.93 \\
\hline $\mathrm{AL}$ & 1.326 & 0.818 & 0.11 & 0.365 & 0.601 & 0.54 & -0.268 & 0.906 & 0.77 & D & 0.231 & 0.046 & 0.00 & 0.251 & 0.047 & 0.00 & 0.275 & 0.040 & 0.00 \\
\hline In AI & -0.022 & 0.026 & 0.39 & 0.028 & 0.018 & 0.11 & -0.004 & 0.020 & 0.86 & S & -0.272 & 0.052 & 0.00 & -0.254 & 0.043 & 0.00 & -0.222 & 0.034 & 0.00 \\
\hline n AS & 0.003 & 0.021 & 0.89 & -0.017 & 0.017 & 0.30 & -0.017 & 0.022 & 0.45 & $\mathrm{R} 1$ & 0.019 & 0.038 & 0.62 & -0.008 & 0.038 & 0.83 & -0.089 & 0.052 & 0.09 \\
\hline In AR & 0.024 & 0.010 & 0.02 & 0.017 & 0.009 & 0.06 & 0.011 & 0.013 & 0.40 & $\mathrm{R} 2$ & -0.007 & 0.038 & 0.86 & -0.024 & 0.042 & 0.56 & -0.117 & 0.045 & 0.01 \\
\hline $\ln \mathrm{AP}$ & 0.091 & 0.042 & 0.03 & 0.082 & 0.038 & 0.03 & 0.061 & 0.047 & 0.19 & R3 & 0.015 & 0.032 & 0.64 & 0.077 & 0.036 & 0.03 & -0.080 & 0.055 & 0.14 \\
\hline$C^{2}$ & 1.219 & 0.963 & 0.21 & 2.706 & 1.400 & 0.05 & -3.046 & 1.642 & 0.06 & $\ln \mathrm{POP}$ & -0.013 & 0.032 & 0.68 & 0.049 & 0.023 & 0.03 & 0.076 & 0.027 & 0.01 \\
\hline $\mathrm{C} \cdot \mathrm{AL}$ & 7.862 & 4.745 & 0.10 & -3.220 & 3.484 & 0.36 & -6.706 & 6.283 & 0.29 & UE & -0.807 & 1.179 & 0.49 & -2.820 & 1.313 & 0.03 & 1.527 & 2.125 & 0.47 \\
\hline$C \cdot \ln A I$ & -0.109 & 0.172 & 0.53 & 0.115 & 0.109 & 0.29 & -0.372 & 0.181 & 0.04 & $\ln I N C$ & -0.307 & 0.142 & 0.03 & -0.091 & 0.136 & 0.50 & -0.092 & 0.167 & 0.58 \\
\hline$C \cdot \ln$ AS & 0.071 & 0.113 & 0.53 & -0.173 & 0.101 & 0.09 & 0.157 & 0.137 & 0.25 & DV & -22.144 & 8.559 & 0.01 & -9.545 & 5.825 & 0.10 & -5.854 & 9.658 & 0.54 \\
\hline$C \cdot \ln \mathrm{AR}$ & -0.013 & 0.053 & 0.81 & 0.058 & 0.058 & 0.32 & -0.139 & 0.072 & 0.05 & $\mathrm{CH}$ & -0.064 & 0.113 & 0.57 & 0.111 & 0.076 & 0.15 & 0.028 & 0.099 & 0.78 \\
\hline $\mathrm{C} \cdot \ln \mathrm{AP}$ & 0.025 & 0.283 & 0.93 & 0.118 & 0.268 & 0.66 & 0.626 & 0.321 & 0.05 & DVH & 1.110 & 7.877 & 0.89 & 3.980 & 4.010 & 0.32 & -4.138 & 7.376 & 0.57 \\
\hline$C \cdot \ln \mathrm{K}$ & 0.007 & 0.075 & 0.92 & -0.003 & 0.044 & 0.95 & -0.005 & 0.047 & 0.91 & & & & & & & & & & \\
\hline$C \cdot \ln L$ & 0.064 & 0.062 & 0.31 & 0.035 & 0.036 & 0.34 & 0.024 & 0.056 & 0.67 & & & & & & & & & & \\
\hline$C \cdot \ln E$ & -0.004 & 0.117 & 0.97 & -0.005 & 0.067 & 0.94 & -0.002 & 0.078 & 0.98 & Generalized & & & 0.998 & & & 0.998 & & & 0.998 \\
\hline$C \cdot \ln M$ & 0.036 & 0.042 & 0.39 & 0.024 & 0.038 & 0.54 & -0.004 & 0.046 & 0.94 & Equation Adj & justed $\mathrm{R}^{2}$ & & & & & & & & \\
\hline $\mathrm{AL} \cdot \ln \mathrm{K}$ & -0.505 & 0.599 & 0.40 & -0.097 & 0.226 & 0.67 & 0.169 & 0.713 & 0.81 & Productior & n Function & & 0.941 & & & 0.946 & & & 0.937 \\
\hline $\mathrm{AL} \cdot \ln \mathrm{L}$ & -1.369 & 0.538 & 0.01 & 0.010 & 0.273 & 0.97 & 0.334 & 0.497 & 0.50 & Capital Cos & st Share & & 0.746 & & & 0.763 & & & 0.676 \\
\hline $\mathrm{AL} \cdot \ln \mathrm{E}$ & -0.002 & 0.937 & 1.00 & -0.011 & 0.415 & 0.98 & -0.025 & 0.752 & 0.97 & Labor Cost & t Share & & 0.655 & & & 0.646 & & & 0.621 \\
\hline $\mathrm{AL} \cdot \ln \mathrm{M}$ & -1.371 & 0.488 & 0.01 & -0.417 & 0.244 & 0.09 & -0.044 & 0.479 & 0.93 & Materials & Cost Share & & 0.803 & & & 0.837 & & & 0.790 \\
\hline
\end{tabular}

